\title{
Monitoring the Sequelae of Coronary Microembolization on Myocardium Using Noninvasive Imaging (Review)
}

\author{
M. Saeed*, M. W. Wilson \\ Interventional Radiology Laboratory, Department of Radiology and Biomedical Imaging, University of California, \\ San Francisco, CA, USA \\ Email: ${ }^{*}$ maythem.saeed@ucsf.edu
}

Received 5 September 2014; revised 21 October 2014; accepted 6 November 2014

Copyright (C) 2014 by authors and Scientific Research Publishing Inc.

This work is licensed under the Creative Commons Attribution International License (CC BY). http://creativecommons.org/licenses/by/4.0/

(c) (i) Open Access

\begin{abstract}
Acute myocardial infarction (AMI) is a leading cause of death worldwide. It has been clinically classified into 1) ischemic from a primary coronary event (e.g., plaque rupture or thrombotic occlusion), 2) ischemic from a supply-and-demand mismatch and c) ischemic from a percutaneous coronary interventions (PCI). Catheter-based PCI has been frequently used as an alternative to conventional bypass surgery for patients at high risk. However, this method of treatment is associated with microvascular obstruction (MVO) by dislodged microemboli that results in left ventricular (LV) dysfunction/remodeling, perfusion deficits, microinfarction and arrhythmia. The contributions of microemboli after revascularization of AMI have been acknowledged by major cardiac and interventional societies. Recent studies showed that Emboli Detection and Classification (EDAC) Quantifier offers increased sensitivity and capability for detecting dislodged coronary microemboli during PCI. Coronary microembolization can be detected directly by monitoring intramyocardial contrast opacification on contrast echocardiography, increasing F-18 fluorodeoxyglucose (FDG) uptake on positron emission tomography, loss/diminution of signal on first pass perfusion and hypoenhanced zone on contrast enhanced magnetic resonance imaging (MRI) and multidetector computed tomography (MDCT) and indirectly by ST-segment elevation on electrocardiography (ECG). The relations between volumes/sizes of microemboli, visibility of microinfarct, myocardial perfusion and LV function are still under intensive discussions. Non-invasive imaging can play important role in assessing these parameters. This review shed the light on the techniques used for detecting coronary microemboli, microvascular obstruction and microinfarct and the short- and long-term effects of microemboli on LV function, structure and perfusion.
\end{abstract}

\section{Keywords}

Coronary Artery Disease, Coronary Emboli, Interventions, Magnetic Resonance Imaging and

*Corresponding author.

How to cite this paper: Saeed, M. and Wilson, M.W. (2014) Monitoring the Sequeale of Coronary Microembolization on Myocardium Using Noninvasive Imaging. World Journal of Cardiovascular Diseases, 4, 601-622. 


\section{Multi-Detector Computed Tomography}

\section{Introduction}

One in six deaths among Americans is caused by coronary artery disease [1]. Treatment of acute myocardial infarction (AMI) includes revascularization therapy using bypass surgery, balloon angioplasty or stenting. Microvascular obstruction (MVO) is an established complication of revascularization therapy for AMI. A recent study, however, showed that MVO is ischemic injury and not exclusive to revascularization therapy [2]. Furthermore, MVO was observed in a wide range of diseases such as valvular disease, endocarditis, cardiomyopathy with mural thrombus and arrhythmias [3]-[9]. It has also been reported in patients with hypertension, diabetes [10], systemic lupus erythematosus [11] and sickle cell disease [12]. Thus, early detection of dislodged coronary microemboli and visualization of microinfarct are necessary for preventing and treating the side effects of coronary microemboli.

The European Society of Cardiology [13] advocates four reperfusion strategies for acute ST-segment elevation myocardial infarction (STEMI): primary percutaneous coronary interventions (PCI), thrombolysis, rescue coronary angioplasty and late PCI ( $>12$ hours after symptoms). Investigators found that the total volume of microemboli dislodged from ruptured plaque is a key event in formation of MVO, microinfarction, LV dysfunction [10] [14]-[18], arrhythmia [19] [20] and sudden death [16] [21] [22]. Okamura et al. found that distal embolization occurs at high frequently (87\%) during PCI procedure and the number of microemboli is the greatest after stenting [23], because hard stent mash crushes plaque, squeezes plaque particles through the gaps between stent struts. Mechanical obstruction of the microvessel lumen by microemboli (leukocytes, erythrocytes, fibrin and platelet thrombi) and endothelial damage underly the formation of MVO. The exact time course of changes leading to patchy or diffuse MVO, however, are unknown because endothelial damage is induced by intracellular calcium overload, opening of the mitochondrial permeability transition pore, the release of oxygen free radicals and tumor necrosis factor. The variability of atherosclerosis plaque content, type of stent and degree of mechanical compression explain the difference in myocardial response. Kleinbongard et al. [24] recently showed that stent implantation into atherosclerotic plaques releases vasoactive agents (such as serotonin, thromboxane and tumor necrosis factor (TNF $\alpha$ ) that contribute to further impairment in myocardial perfusion. These findings were confirmed in multiple studies that showed substantial number of patients with AMI experience major cardiac events after PCI [25]-[34] and these events continued during follow-up [35]-[39].

Myocardial ischemia/reperfusion and coronary microemboli impact not only the myocardium but also coronary microvessels. MVO is the most severe form of reperfusion injury [40], which is resulted primarily from debris [41], platelet aggregates [42], vasoconstriction [24] and/or damaged vascular endothelium [43]. MVO can happen during primary and elective PCI. Investigators found that MVO is a complex pathologic process and the main components are distal atherothrombotic embolization, ischemic injury, reperfusion injury and susceptibility of coronary microcirculation to injury [44]-[46]. Increased local release of platelet- and endothelium-derived microemboli into the coronary microvessels has also been identified in patients undergoing primary PCI for AMI and correlated to indices of MVO, such as TIMI frame count, myocardial blush grade and electrocardiogram ST-segment resolution [47].

\section{Microemboli and Cardiac Injury Biomarkers}

Measurements of plasma creatine kinase and troponin I are routinely used before and after coronary interventions to provide evidence of myocardial injury [48] [49]. Clinical and experimental studies have reported close relationship between MR-defined large infarct size and serum level of creatine kinase MB and troponin I [50] [51]. However, this relationship seems not be robust in NSTEMI patients with small infarct size [52].

An experimental study showed that the concentrations of troponin I $(0.52 \pm 0.28 \mathrm{ng} / \mathrm{ml})$ and creatine-kinase MB $(1670 \pm 370 \mathrm{U} / \mathrm{L})$ in animals received $16 \mathrm{~mm}^{3}$ were not sigificantly different from animals received $32 \mathrm{~mm}^{3}$ (creatine-kinase $=1060 \pm 235 \mathrm{U} / \mathrm{L}$ and troponin $\mathrm{I}=0.68 \pm 0.4 \mathrm{ng} / \mathrm{ml}$ ) at $24 \mathrm{hrs}$, suggesting that that creatine kinase MB and troponin I have limited sensitivity for differentiating the effects of different microemboli volumes [53]. Another short coming of cardiac injury biomarkers is demonstrated in the kinetics of creatine kinase 
MB and troponin I. Investigators found that both injury biomarkers are significantly higher at 18 - 24 hours compared with controls or baseline data. However, there was no significant difference in creatine-kinase-MB or troponin I levels between solely microembolized myocardium and AMI superimposed with similar volume of microemboli. At 68 - 72 hours, creatine-kinase-MB returned to baseline level, while troponin I remained high in animals subjected to double insult compared with single insult [54].

Mehran et al. found after PCI that plaque burden, measured on intravascular ultrasound (IVUS), closely correlated with the elevation of creatine-kinase MB [55] [56]. The DEDICATION trial, evaluating patients randomized to distal protection using a filter wire protection device versus standard PCI without distal protection, showed no significant difference in cardiac biomarker elevation [57]. Kunadian et al. [58] confirmed these data in meta-analysis study, where the use of distal protection devices resulted in no decrease of early mortality or recurrent myocardial infarction rate.

\section{Coronary Microemboli}

Spontaneous coronary microembolization occurs at any time in diseased arteries despite antiplatelet therapy. Coronary microembolization has been confirmed in patients who died from sudden cardiac death [16] [22] and the average size of microemboli was $250 \mu \mathrm{m}$ [59]. Okamura et al. found on IVUS that the size of microemboli ranges between $47-2503 \mu \mathrm{m}$ [60]. The size and number of detached emboli is key in the formation of MVO zone in AMI, patchy microinfarction, LV dysfunction [10] [14]-[18], arrhythmia [19] [20] and sudden death [16] [21] [22].

MVO refers to suboptimal regional perfusion of infarct-related artery in the presence of patent epicardial coronary circulation. Investigators found that sponteneous plaques and debris are more common in arteries with plaque erosion than plaque rupture [61]. Cardiologists also observed that acute ST-elevation myocardial infarction (STEMI) results from coronary atherosclerotic plaque disruption.

Furthermore, coronary microemboli is considered to be inevitable during PCI revascularization of obstructive atherosclerotic plaque [62], because plaques and debris are disrupted during the passage of guide-wires, positioning of the balloon and stent implant. Differentiation of spontaneous from procedural microembolization is difficult because patients arrive to the hospital with pre-existing AMI related to coronary thrombi and PCI revascularization is also associated with microthrombi. Pathological analyses revealed that coronary thrombi consist of platelets, erythrocytes and fibrin, and often contain atherosclerotic inflammatory cells [63] [64]. Microscopic examination revealed that platelet aggregation could be one of the causes of acute coronary syndrome in patients [16] [21] [22]. Additionally, a recent study by Khan et al. showed that the formation of MVO is not exclusive to revascularization therapy [2].

Boese et al. found an association between plaque composition and post-procedural microinfarction [65]-[67]. The components of microemboli, endothelial sloughing, edema and fibrin plugging have significant impact on myocardial perfusion [65] [68]-[72] and may be on the invasion of polymorphonuclear leukocytes, monocytes and macrophages to the extracellular space [16] [22] [70] [72] [73].

\section{Microemboli Visualization}

Direct and indirect evidence of microembolization during PCI comes from distal protection device and IVUSsystem, which reported embolic particle sizes and a typical reversal of systolic flow, delayed diastolic component and visualization of microemboli [74]-[76]. Microemboli create countable signals on the IVUS display due to the higher reflection of sound waves compared to the blood cells. The microembolic signals appear as shortduration, unidirectional, high-intensity signals within the flow spectrum on the fast Fourier transform spectral display.The intensity of the backscatter signal is processed into gray scale with a spatial resolution of $150 \mu \mathrm{m}$ at a frame rate of 10 - 30 frames/s. This new technique can also identify and quantify various plaque components in patients [77]-[81]. It can detect features associated with plaque vulnerability, such as an eccentric pattern; the presence of an echolucent core, probably representing the lipid-rich core; positive vessel wall remodeling, defined by the expansion of the overall vessel without compromising the lumen [82]; presence of thrombi [83][85]; lumen narrowing [84]; and a spotty pattern of calcifications [86]. Thus, Doppler ultrasound technique became the gold standard method to quantify microemboli in real-time.

MRI and MDCT, positron emission tomography (PET) and single photon emission computed tomography 
(SPECT) are associated with unique imaging properties and exhibit variable sensitivity and specificity to cardiac pathologies [87]-[94]. Cardiovascular MRI and MDCT scanners offer a higher spatial resolution than nuclear medicine techniques. MRI based on 3D datasets is considered the gold standard for volumetric and functional analysis of cardiac chambers. In addition, MRI is a versatile technique that has the ability to assess viability on delayed contrast enhancement, LV function on cine, 3D strain with saturation tagged and phase contrast velocity encoded sequences and perfusion on first pass contrast media [95].

MRI, MDCT have been used for detecting microinfarct [71] [96]-[99]. These noninvasive methods can be used alternatively in patients with contraindications to iodinated or gadolinium-based contrast agents. MRI has inherent strengths over the other clinically approved modalities that include: 1) the absence of radiation exposure, which is a strong motivation to further work on implementing MRI after PCI; 2) the lack of administration of nephrotoxic iodinated contrast media; 3) MRI is the method of choice for assessment of LV function and myocardial viability; 4) signal intensity differences of nearly 2 - 5 fold were identified between viable and non-viable myocardium; 5) serial assessments; 6) the potential to measure three dimensional (3D) strain at rest and dobutamine stress; and 7) acquisition of images in any plane negates the need for post imaging reconstruction of images. The advantages of using MDCT include: a) MDCT angiography is the method of choice for direct visualization of coronary calcium and atherosclerosis; b) the presence of LV assist devices do not preclude the performance of MDCT imaging; c) the relatively fast acquisition time (7 - $10 \mathrm{~min}$ ) compared with cardiac MRI (45 min), leads to patient's comfort as well as cost and time savings; d) scanning of claustrophobic or uncooperative patients; e) less technical and personnel requirements for MDCT studies; f) life-support and physiologic-monitoring equipment can be placed close to MDCT scanners and g) iodinated contrast media provide linear relationship between attenuation and concentration on first pass perfusion MDCT [100].

\section{Microvascular Obstruction and Microinfarction}

The coronary artery tree consists of large epicardial arteries and microvessels. The range of epicardial coronary artery diameter varies between a few millimeters to $400-500 \mu \mathrm{m}$ and these vessels are visible on the current imaging modalities, but not microvessels between 8 - $120 \mu \mathrm{m}$. Advanced real-imaging techniques helped in accurately determining coronary artery diameter that led to reduce the use of oversized stent or higher pressures resulting in emboli being sloughed into the lumen of the artery.

Galiuto classified microvascular damage after revascularization into structural (irreversible) and functional (reversible), where the structural damage is related to damage of microvascular walls; conversely, the functional damage is related to edema and cellular plugging [101]. De Maria et al. showed the similarity in the sequelae of spontaneous and procedural distal microembolization [62]. Jaffe et al. described two pattens of MVO, namely zonal MVO located in the core of pre-existing infart (primery PCI) and patchy MVO located in ischemic myocardium (elective PCI) [44]. A schematic figure shows both patterns of infarcts in pre-existing infart superimposed with microemboli (Figure 1). Microinfarct has been recognized on MRI in patients after PCI [15] [17] [95]. Visualization of patchy microinfarct on contrast enhanced MRI and MDCT depends on multiple factors; namely spatial resolution, extent of microinfarct and imaging time after embolization (Figure 2).

In experimental animal studies, MRI and MDCT demonstrated microinfarct, result from patchy MVO, as differentially enhanced speck with heterogeneou pattern in the ischemic-related artery [53]. Acute microinfarct on histochemical and histological stains was defined as unstained necrotic speck $\left(0.7-7 \mathrm{~mm}^{2}\right.$ in size $)$ and patchy violate-blue myocytes surrounding obstructed microvessels, respectively (Figure 3) [53].

Investigators also assessed the sensitivity of MRI and MDCT techniques in visualizing patchy microinfarct using different volumes/sizes of microemboli and determined the cutoff of microemboli volume that provides reproducible visible microinfarct [53] [54] [102]-[105]. We found that both visible and non-visible microinfarct on MRI and MDCT have short- and long-term side effects [53] [54] [104] [105].

Also of clinical significance is patchy MVO at the peri-infarct zone, where, this zone contains an admixture of viable and nonviable myocytes that provides a suitable environment for the development of LV arrhythmia [106] [107]. The mechanism underlying hypokinesia in the peri-infarction zone is not well defined. Several hypotheses have been proposed, including changes in mechanical load leading to cellular hypertrophy and dysfunction [108], reduced coronary reserve [109], increased systolic wall stress [110], oxidative stress, and inflammation [111]. Microscopic examination of the peri-infarct zone revealed sporadic non-patent microvessels microemboli. 


\section{MVO zone and patchy MVO in AMI} after PCI revascularization
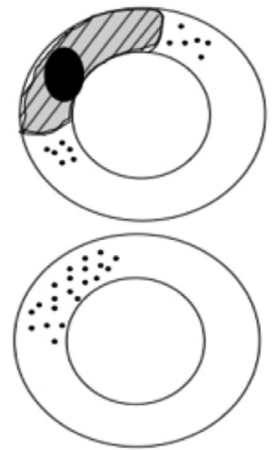

Patchy MVO after PCI revascularization of stenosed coronary artery

Figure 1. The two types of MVO are: MVO zone in the core of AMI (dark zone) and the patchy MVO (dotted) after PCI revascularization of stenosed coronary artery without infarct.

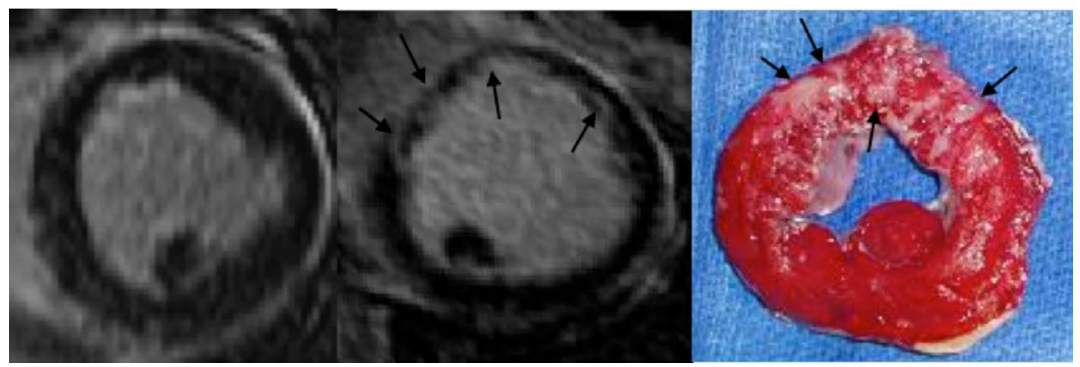

Figure 2. Contrast enhanced MR images of myocardial microinfarct acquired at $1 \mathrm{hr}$ (left) and 7 days after coronary embolization (middle). The speck of microinfarct are visible at 7 days (arrows), but not at $1 \mathrm{hr}$, after embolization. A corresponding left ventricle section stained with a triphenyltetrazolium chloride stain shows patchy microinfarct at 7 days (arrows, right).
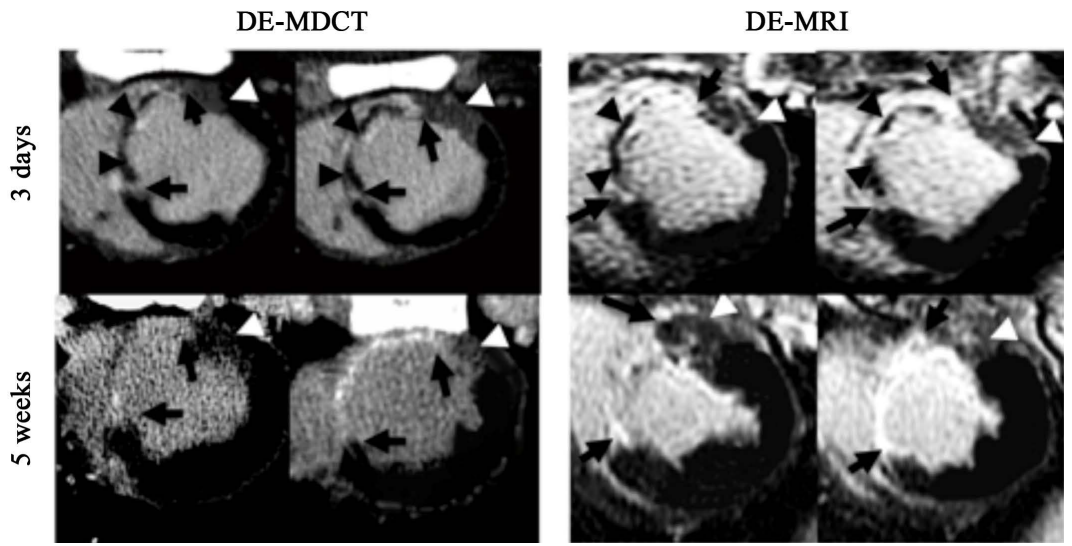

Figure 3. Contrast enhanced MDCT (left block) and MRI (right block) were obtained from a representative animal subjected to myocardial infarct superimposed with microembolization. At 3 days (top row), the images showed hyperenhanced MI (black arrows), hypoenhanced MVO (black arrowhead) and moderately patchy microinfarct at the peri-infarct zone (white arrowhead). At 5 weeks (bottom row), both imaging modalities showed wall thinning in MI (black arrows), moderately enhanced microinfarct at the peri-infarct zone (white arrowhead) and hypertrophy in remote myocardium. 
Unlike microscopy, MRI and MDCT indirectly demonstrated sporadic MVO by visualization patchy microinfarct.

\section{Microemboli and Infarct Healing}

Our understanding of coronary microvasculature in patients has been limited partly due to inability to non-invasively visualize the anatomy of microvascular bed and its complicated functional pathways. On the other hand, acute and scar myocardial infarct are discriminated on noninvasive imaging. Choi et al. [112] and Inkangisorn et al. [113] monitored the healing of myocardial infarct on delayed contrast enhanced MRI. They found a decline of $27 \%-31 \%$ in the extent of myocardial infarct over the course of 2 months in patients. Furthermore, myocardial infarct is associated with MVO [114], which occurs in $40 \%-60 \%$ of patients treated by PCI. Other investigators found that the extent of myocardial infarct on MRI decreases by $21 \%-30 \%$ in humans during the first week following treatment for STEMI [115], while MVO reduced by $48 \%$ in humans [116] and $67 \%$ in animals [117].

In recent studies, we found that MVO zone in AMI delays infarct healing, accentuates LV remodeling and hypertrophy of romote myocardium compared with infarct with negligable MVO [118] (Figure 4). The difference in the speed of healing is most likely related to slow delivery of nutrients and inflammatory cells to remove the debris [119] [120], while the accentuation in LV hypertrophy is compensatory to infarct thinning and buldging. Infarct size [121] [122] and MVO [60] [121] [123] [124] are powerful predictors of adverse LV remodelling and prognosis.

\section{Microemboli and Perfusion}

PCI partially restores flow in the infarct-related artery with persistent ST-segment elevation, abnormal myocardial blush grade and abnormal TIMI frame count, due to distal embolization [125]. Lund et al. [126] observed
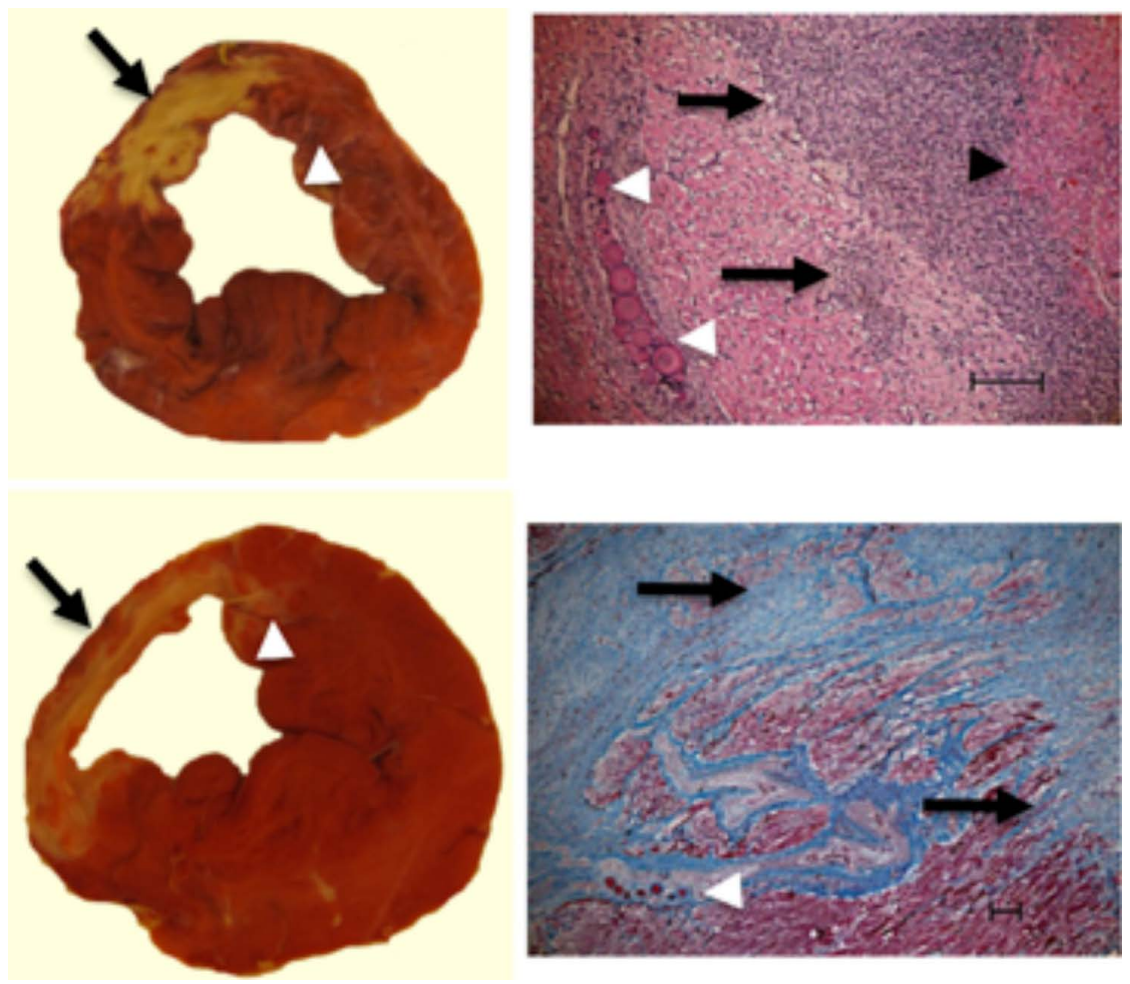

Figure 4. Histochemical TTC stain shows the difference in wall thickness and extent of MI between 3 days (top row, group II) and 5 weeks (bottom row, group III). Histopathological stains (Hematoxylin/eosin and Masson trichrome) show the peri-infarct zone and scar infarct over the course of 5 weeks. Black arrow $=$ infarct, black arrowhead = hemorrhage, white arrowhead = microemboli obstructing blood vessels. 
that the perfusion in AMI is spatially and temporally complex with regions of hyperaemia, low flow and MVO. Selvanayagam et al. [17] observed a decline in perfusion reserve in myocardial segments that showed new microinfarct resulted from microemboli after PCI. Porto et al. [15] used ultrasonography and delayed contrastenhanced imaging after PCI for determining the relationship between the extent of microinfarct and plaque volumes. A positive correlation was found between the two parameters.

Several studies showed the perfusion deficit in embolized myocardium [70] [71] and increase in epicardial coronary flow [73], which was linked to the release of adenosine in ischemic myocardium [18] [127]. Experimental studies confirmed the persistent regional perfusion deficit in AMI, patchy microinfarct (Figure 5) [54] [71] and AMI superimposed with microemboli [54], which are reflected on perfusion indices (max upslope, max signal intensity/attenuation and time to peak). Table 1 shows the regional changes in peak signal attenuation and signal intensity on MDCT (in Hounsfield units) and MRI (in arbitrary units), respectively) as a function of time in animals subjected to 90 min LAD occlusion plus microembolization and reperfusion. The perfusion data show the deficits in perfusion of the infarct and peri-infarct myocardium over time compared to remote myocardium.

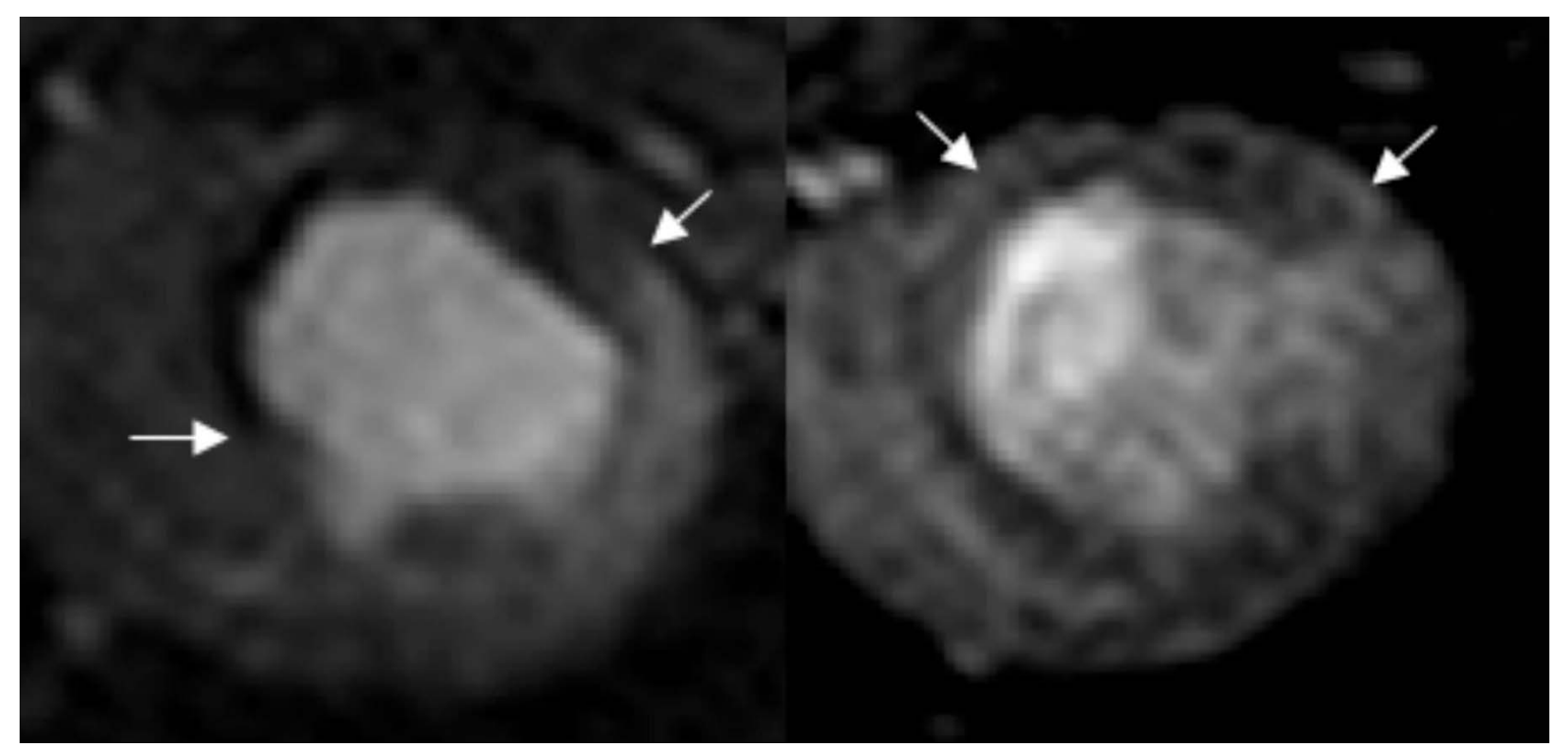

Figure 5. Myocardial perusion deficits (arrows) are shown at the peak of remote myocardial enhancemet at 1 (left) and 7 (right) days after coronary embolization in swine model.

Table 1. MDCT peak signal attenuation Hounsfield units (HU) of animals subjected to LAD occlusion/reperfusion plus microembolization ischemic insult at 3 days and 5 weeks of Groups II and III.

\begin{tabular}{|c|c|c|c|}
\hline & Group II 3 days & Group III 3 days & Group III 5 weeks \\
\hline \multicolumn{4}{|l|}{ MDCT } \\
\hline Remote myocardium & $150 \pm 7$ & $123 \pm 3$ & $115 \pm 1^{* \dagger}$ \\
\hline Peri-infarct zone & $89 \pm 7^{\#}$ & $104 \pm 4^{\#}$ & $114 \pm 3^{*+\#}$ \\
\hline Infarct & $61 \pm 7^{\dagger \S \#}$ & $88 \pm 4^{\dagger \S \#}$ & $89 \pm 1^{\dagger \S \#}$ \\
\hline \multicolumn{4}{|l|}{ MRI } \\
\hline Remote myocardium & $1432 \pm 77$ & $1442 \pm 67$ & $1515 \pm 195$ \\
\hline Peri-infarct zone & $1041 \pm 72^{\#}$ & $966 \pm 31^{\#}$ & $1277 \pm 71^{*+\#}$ \\
\hline Infarct & $806 \pm 58^{\dagger \S \#}$ & $732 \pm 58^{\dagger \S \#}$ & $1017 \pm 79^{*+\S \#}$ \\
\hline
\end{tabular}

${ }^{*} P<0.02$ compared with 3 days of the same cohort; ${ }^{\dagger} P<0.01$ compared with animals in Group II; ${ }^{\S} P<0.02$ compared with border zone myocardium, ${ }^{\#} P<0.02$ compared with remote myocardium. 


\section{Microemboli and LV Function}

The most clinically used methods for assessing LV function are dobutamine echo-contractile reserve, contrast echo (wall motion) and MRI (wall 3D strain). Quantifying LV function is a powerful predictor of mortality in patients with coronary artery disease [60] [121]. Invasive methods demonstrated the deleterious effects of microembolization on regional and global LV function [18] [128]. The observed changes in LV function were disproportional to the extent of microinfarct.

Noninvasive MRI showed that coronary microemboli cause super-acute (1 hour) acute (3 days), subacute (7 days) and chronic (5 - 8 weeks) impairment in regional and global LV function [54] [69] [73] [129] [130]. It was found that global and regional LV impairment 3 days after LAD microembolization with 16 mm $^{3}$ volume and 40 $120 \mu \mathrm{m}$ diameters is comparable to $90 \mathrm{~min}$ left anterior descending (LAD) coronary artery occlusion/reperfusion, despite the substantial difference in the extents of myocardial damage $(6.5 \% \pm 0.6 \% \mathrm{LV}$ mass versus $12.6 \% \pm$ $1.2 \%, P<0.001$ ) (Figure 6). Other experimental MRI and MDCT studies demonstrated the greater decline in ejection fraction and increase in LV volumes in pre-existing MI with large MVO compared with similar extents of myocardial damageand negligable MVO [104] [105] [118]. Furthermore, animals with negligable MVO showed moderate recovery in ejection fraction over the course of 5 weeks, but not in animals with large MVO.

In 1995, Pfeffer described the complexity of dimensional changes in the LV after AMI [131]. Early techniques for assessing myocardial strain were invasive and included implantable metal [132] or radiopaque [133] markers. Recently, investigators found that cine, tagged and velocity-encoded phase contrast MR pulses have the pontential for quantifying 3 dimensional (3D) LV strain (radial, circumferential and longitudinal) [69] [130] (Figure 7 and Figure 8). These indices are independent of ejection fraction, wall motion or myocardial oxygen consumption [134].
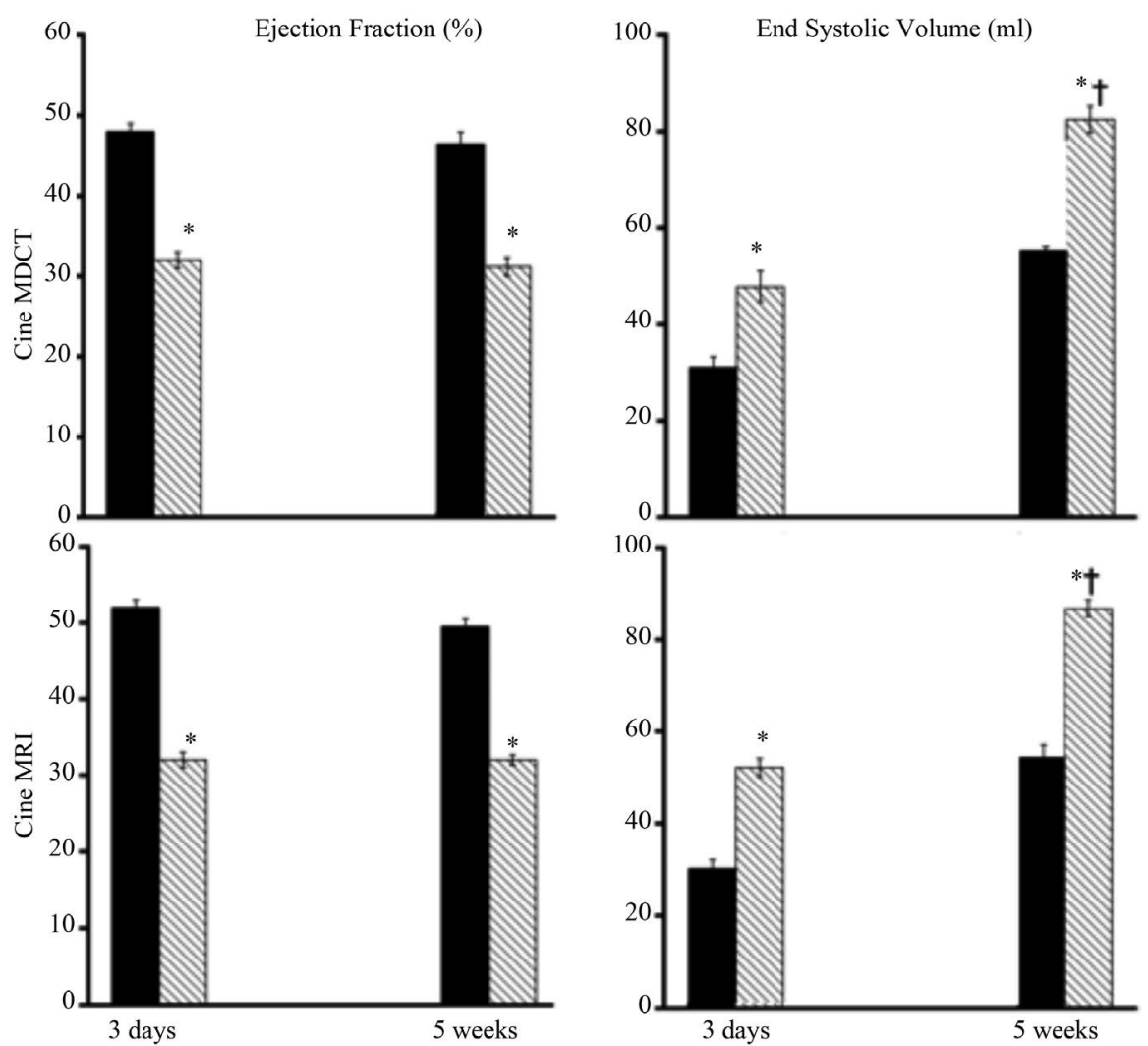

Figure 6. Ejection fraction (\%) and end systolic volume (ml) in Groups I (black column) and III (striped column) measured on cine MDCT (top row) and MRI (bottom row). MI superimposed with microembolization showed persistent decline in ejection fraction (left blocks) and increase in end systolic volume (right blocks). Similar changes in ejection fraction and end systolic volume were observed on both modalities. ${ }^{*} P<0.02$ compared with Group I. ${ }^{\dagger} P<0.02$ compared with the same cohort at 3 days. 


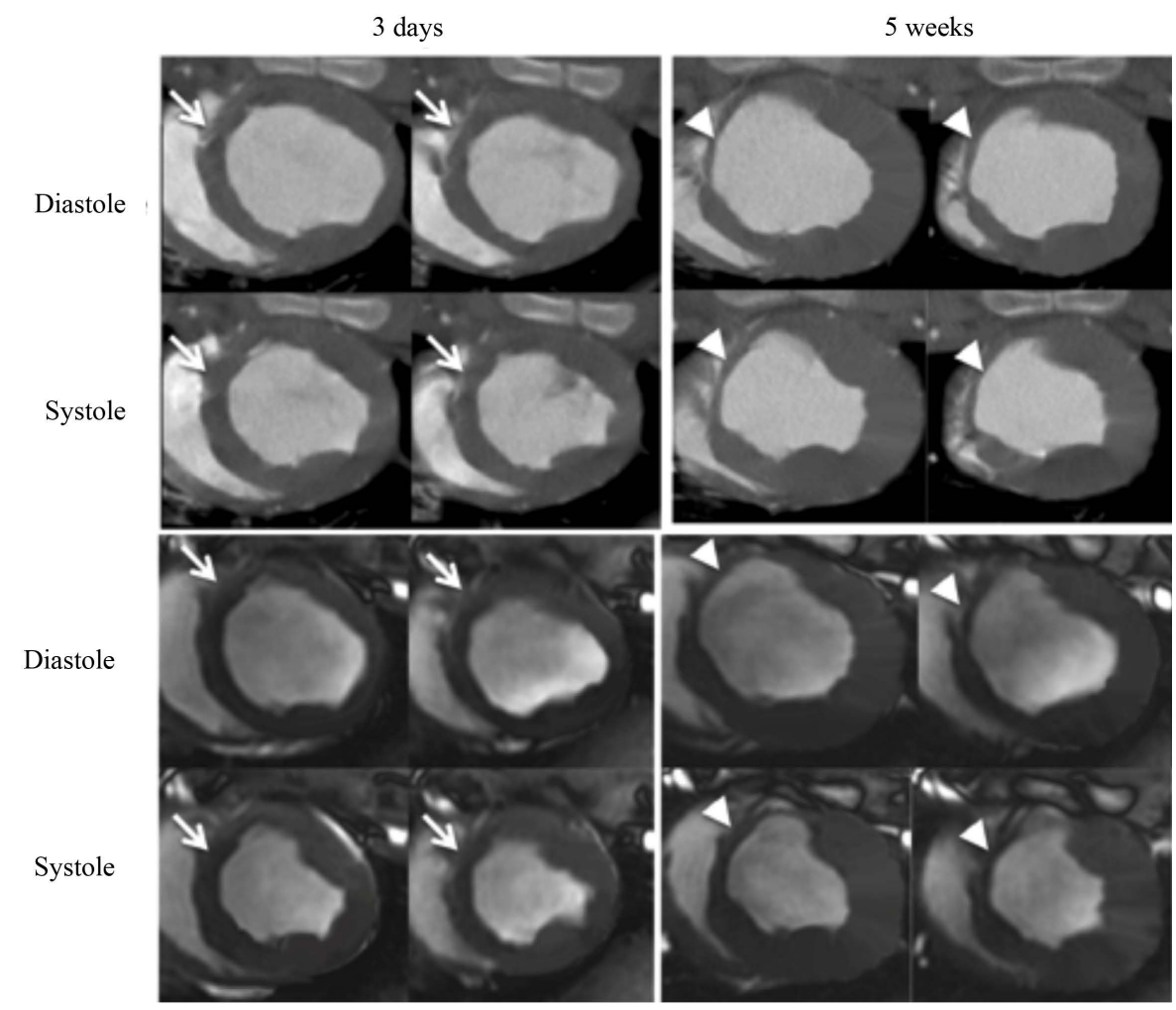

Figure 7. Cine MDCT (top blocks) and MRI (bottom blocks) acquired at 3 days (left blocks) and 5 weeks (right blocks) after embolization of the LAD coronary artery. MDCT and MRI show the lack of systolic wall thickening in the LAD territory at 3 days and 5 weeks. The LAD region (arrows) showed no thinning at 3 days, but at 5 weeks. Compensatory hypertrophy was evident at 5 weeks in remote myocardium.

The circumferential and longitudinal strain on MRI were evaluated in control animals and compared with animals subjected to different ischemic insults; namely solely coronary microembolization, solely LAD occlusion for 90 min followed by reperfusion and 90 min LAD coronary occlusion plus microembolization and reperfusion in a swine model [130]. MRI studies were performed 3 days affter coronary interventions (Figures 9-11). It was found that the impairment in LV circumferential strain and dyssynchrony is comparable between $32 \mathrm{~mm}^{3}$ coronary microemboli and $90 \mathrm{~min}$ occlusion/reperfusion of the same infarct-related artery, despite the difference in the extents of myocardial damage. Furthermore, microemboli caused significant decrease in peak systolic strain rate of remote myocardium. The comparable LV dysfunction in these animals suggests that mechanisms other than the extent of myocardial damage govern LV dysfunction [135], such as the release of tumor necrosis factor (TNF)- $\alpha$ [19] and other inflammatory mediators [136] [137]. Solely microembolized and AMI superimposed with microemboli showed slower systolic strain rate than LAD occluded/reperfused territory, suggesting disproportion between myocardial damage and circumferential strain. In remote myocardium, peak systolic strain rate was significantly decreased in microembolized and combined insult animals, but not in occluded/reperfused animals, compared with controls. Similar to peak systolic strain rate, peak diastolic strain rate in remote myocardium was significantly decreased in animals subjected to microembolization or combined interventions, but not in LAD occluded/reperfused animals. Cine and tagged MRI sequences provided evidence that peak strain and time to peak strain (TTPS) are early predictors of dysfunction. Recent studies showed that the complex contraction pattern of the heart and alterations to this pattern due to various cardiac pathologies could be determined using tagged cine MRI [11]-[13].

\section{Clinical Studies}

Evidence on coronary microembolization in patients came from intravascular imaging, detailing a relationship between plaque volume reduction in the diseased coronary artery after PCI with reduced myocardial reperfusion 


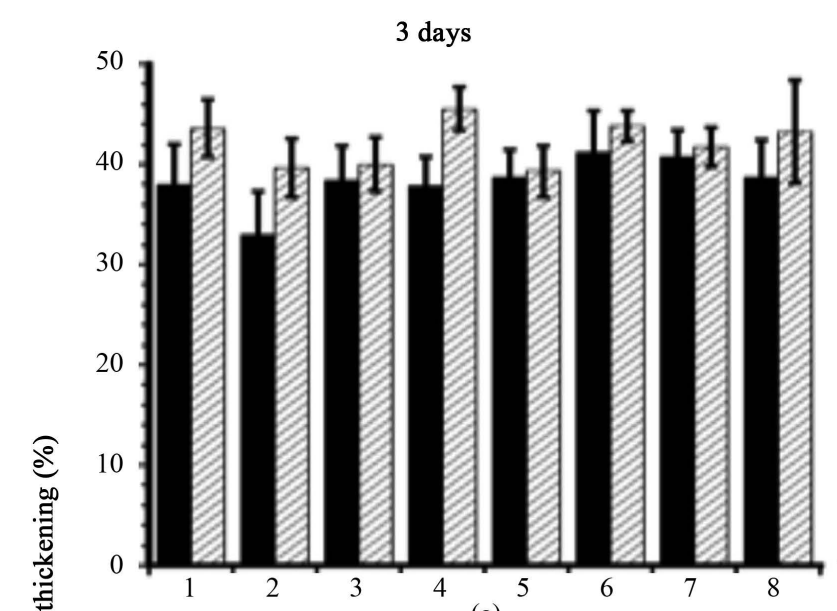

(a)

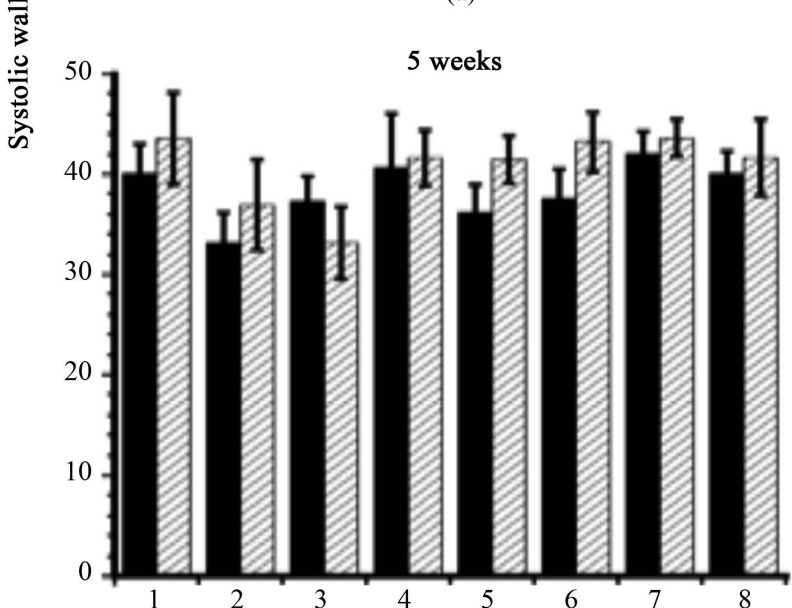

(c)

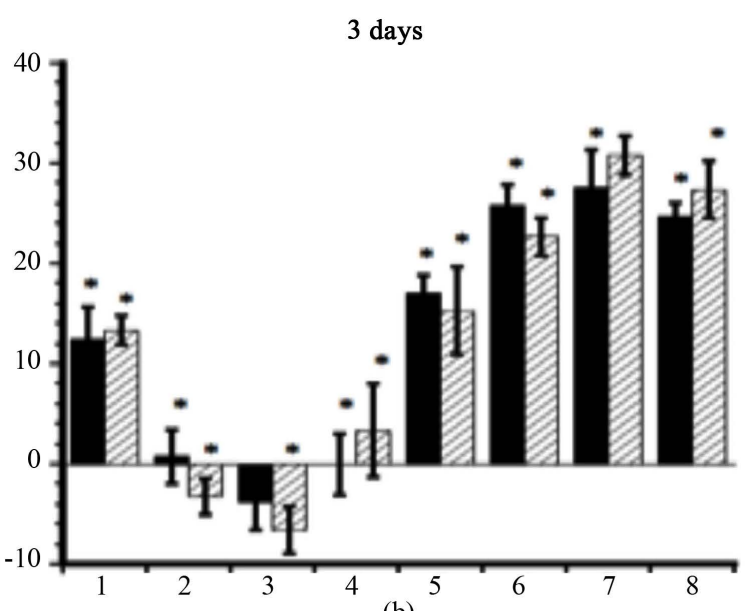

(b)

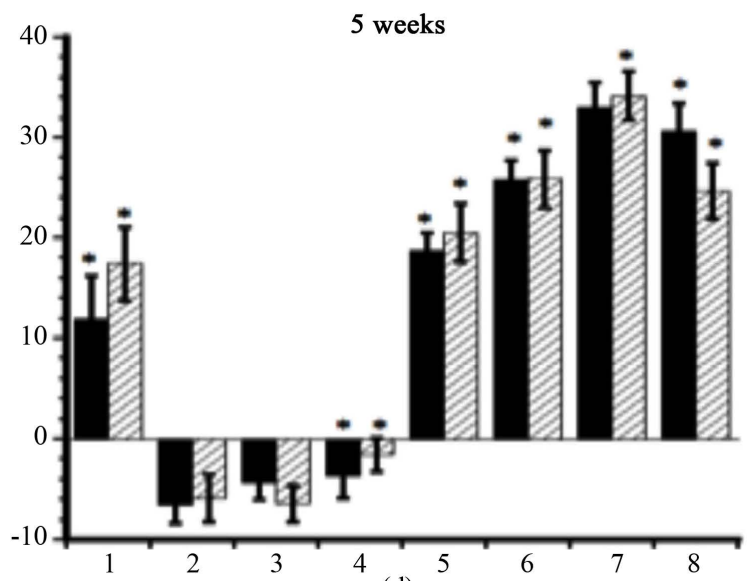

(d)

LV segments

Figure 8. Systolic wall thickening in slices above (a) and (c) and below (b) and (d) the site of occlusion/microembolization/ reperfusion at 3 days (top row) and 5 weeks (bottom row) in Group III. Each LV slice was divided to 8 segments and the segments with dysfunctional LAD territory are located in segments 2, 3 and 4. Similar magnitudes of changes in systolic wall thickening were obtained on MDCT (black bars) and MRI (striped bars). ${ }^{*} P<0.02$ compared with remote myocardium.

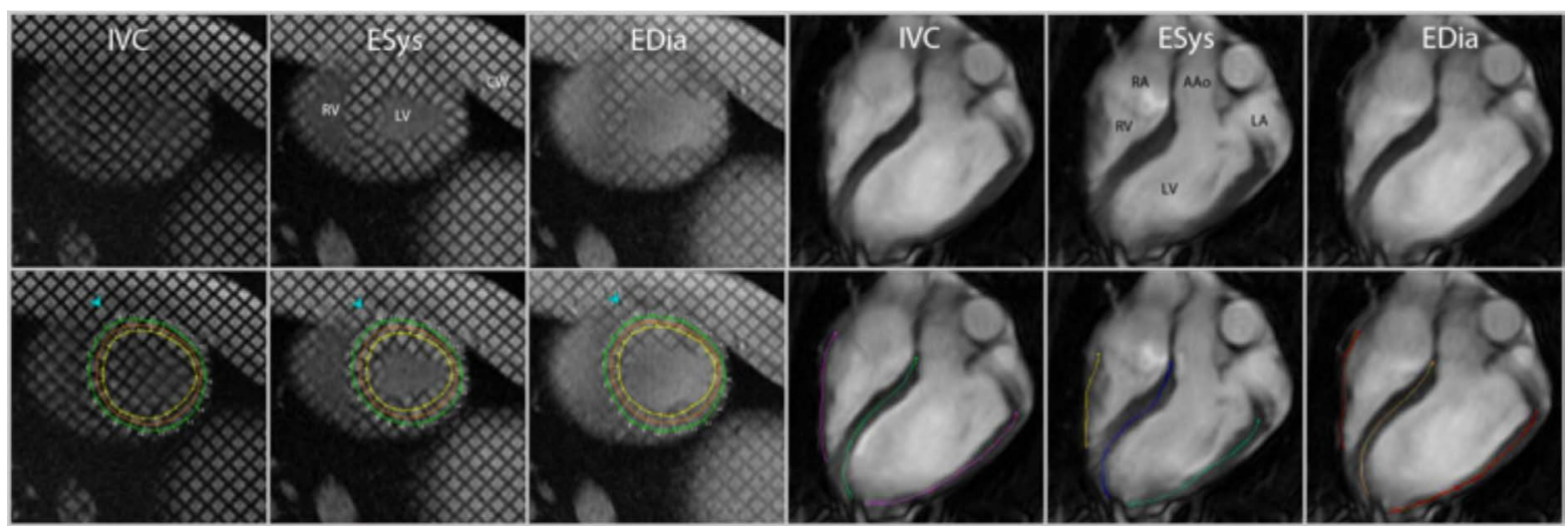

Figure 9. Representative tagged and cine MR images utilizing tracing Method. Top row demonstrates short-axis and long-axis MRI images, while bottom row demonstrates images after tracing of the myocardium using HARP. Left three columns are cine tagged MRI and right three columns are cine MRI. IVC = Isovolumetric Contraction, ESys = End Systole, EDia = End Diastole, LV = Left Ventricle, RV = Right Ventricle, CW = Chest Wall, RA = Right Atrium, LA = Left Atrium, AAo $=$ Ascending Aorta. 

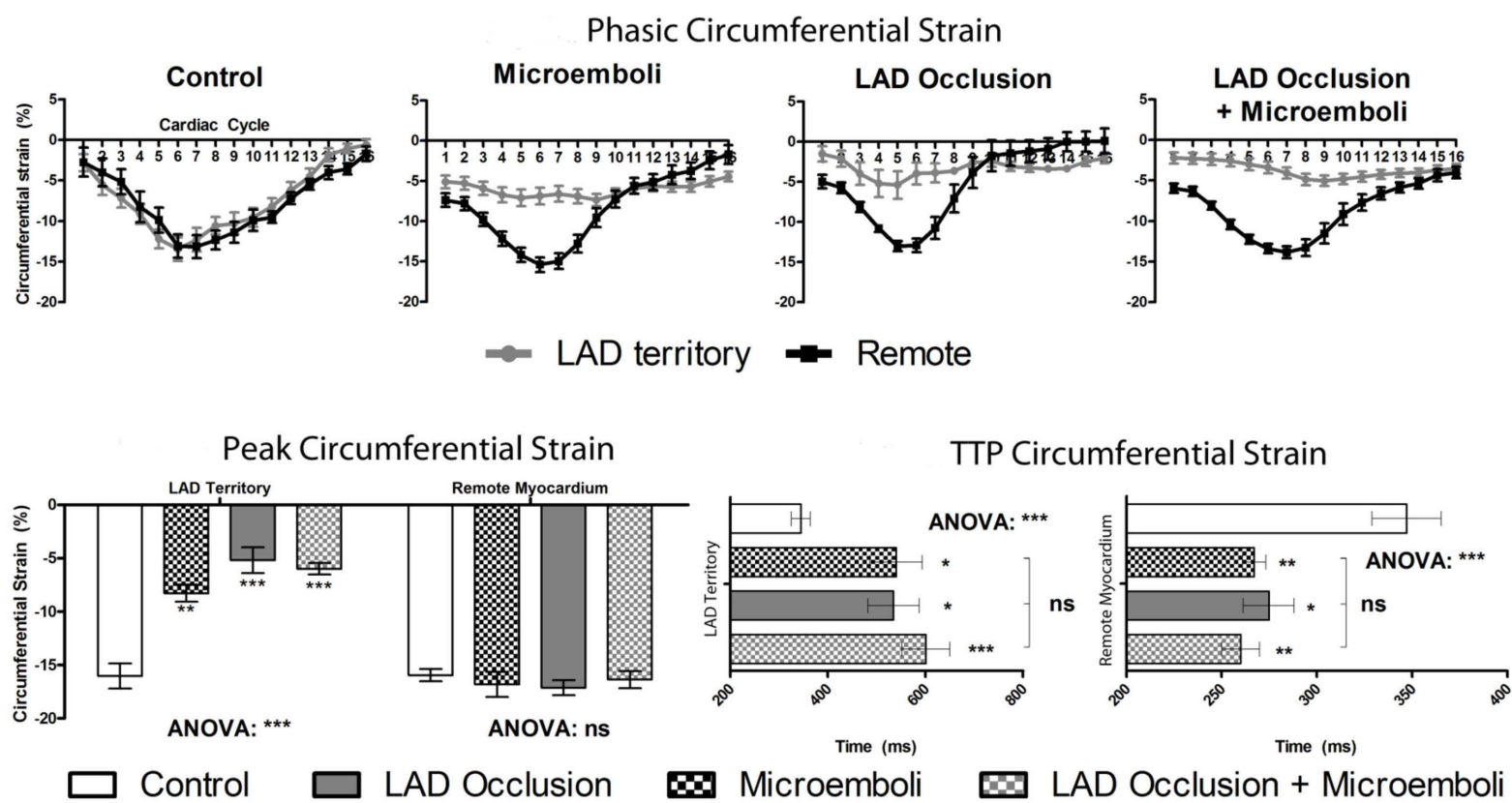

Figure 10. Top row: Phasic circumferential strain peak and rate during R-R interval in LAD territory and remote myocardium of control and animals subjected to microembolization, $90 \mathrm{~min}$ LAD occlusion/reperfusion and the combination. A significantly decreased peak circumferential strain was observed in the LAD territory compared with remote myocardium in all coronary interventions $(P<0.001)$. Bottom left: Bars show average peak circumferential strain. ANOVA showed significant decrease in strain of the LAD territory 3 days after interventions compared with controls. Remote myocardium showed no significant difference between interventions and control. Bottom right: Bars show significant variation in time to peak circumferential strain between remote and LAD territory TTPS. Remote myocardium showed decreased TTPS for all interventions, while the LAD territory demonstrated increase. ${ }^{*} P<0.05,{ }^{* *} P<0.01,{ }^{* * *} P<0.001$.

[138] and formation of new infarction and MVO in patients [15] [139]. The occurrence of plaque rupture with subsequent microemboli of atherosclerotic and thrombolytic debris into small coronary vessels has been confirmed [22] [140]. Enhanced Myocardial Efficacy and Recovery by Aspiration of Liberated Debris (EMERALD) trial reported visible debris in 78\% of patients [141]. Bahrmann et al. demonstrated that the incidence of procedure associated non-ST elevation myocardial infarction is correlated to the frequency of Doppler-detected microemboli [76] [142].

Clinical studies showed substantial difference in the incidence of microembolization from coronary plaques from 30\% [22], 54\% [61] to 81\% [143]. In half of the patients the additional infarct after PCI was interpreted to be caused by occluded side branches, resulting in a $12 \%$ incidence of microinfarction caused by microembolization [15]. Recent studies showed the capability of MRI and MDCT to detecting microinfarct ( $>2 \mathrm{~g}$ ) [71] [96]-[99]. Selvanayagam et al. found a new area of infarct in $28 \%$ of patients after the procedure using contrast enhanced cardiac MRI [144]. The highest incidence was seen in patients who had recent PCI or thrombolysis [143]. Coronary microemboli are considered the primary causes of contractile dysfunction and arrhythmogenesis in the absence of an atherosclerotic obstruction of an epicardial coronary artery [16] [20]. Cardiac MRI has been implemented in measuring perfusion in patients after PCI [17] [145].

Coronary microemboli may explain the cause of mismatch between blood flow in the epicardial coronary arteries and LV function; a phenomenon which has been clinically observed after PCI [146] [147]. Selvanayagam et al. [145] found in 152 patients that even small amounts of procedure-related myocardial injury are associated with poor clinical outcome and concluded that $2 \%-5 \%$ of LV infarct causes disproportional LV dysfunction [110]. Other studies have shown coronary microemboli cause persistent LV dysfunction (heart failure) and in some cases sudden death [25] [26].

The clinical evidence for microembolization after PCI came from the elevation of creatine-kinase in $10 \%$ $40 \%$ of patients [20] [74] [96] [148] [149]. A follow-up study in patients who underwent coronary angioplasty or coronary atherectomy found that the relative risk of cardiac death is increased 2.2-fold in patients whose 
Peak Systolic Circumferential Strain Rate
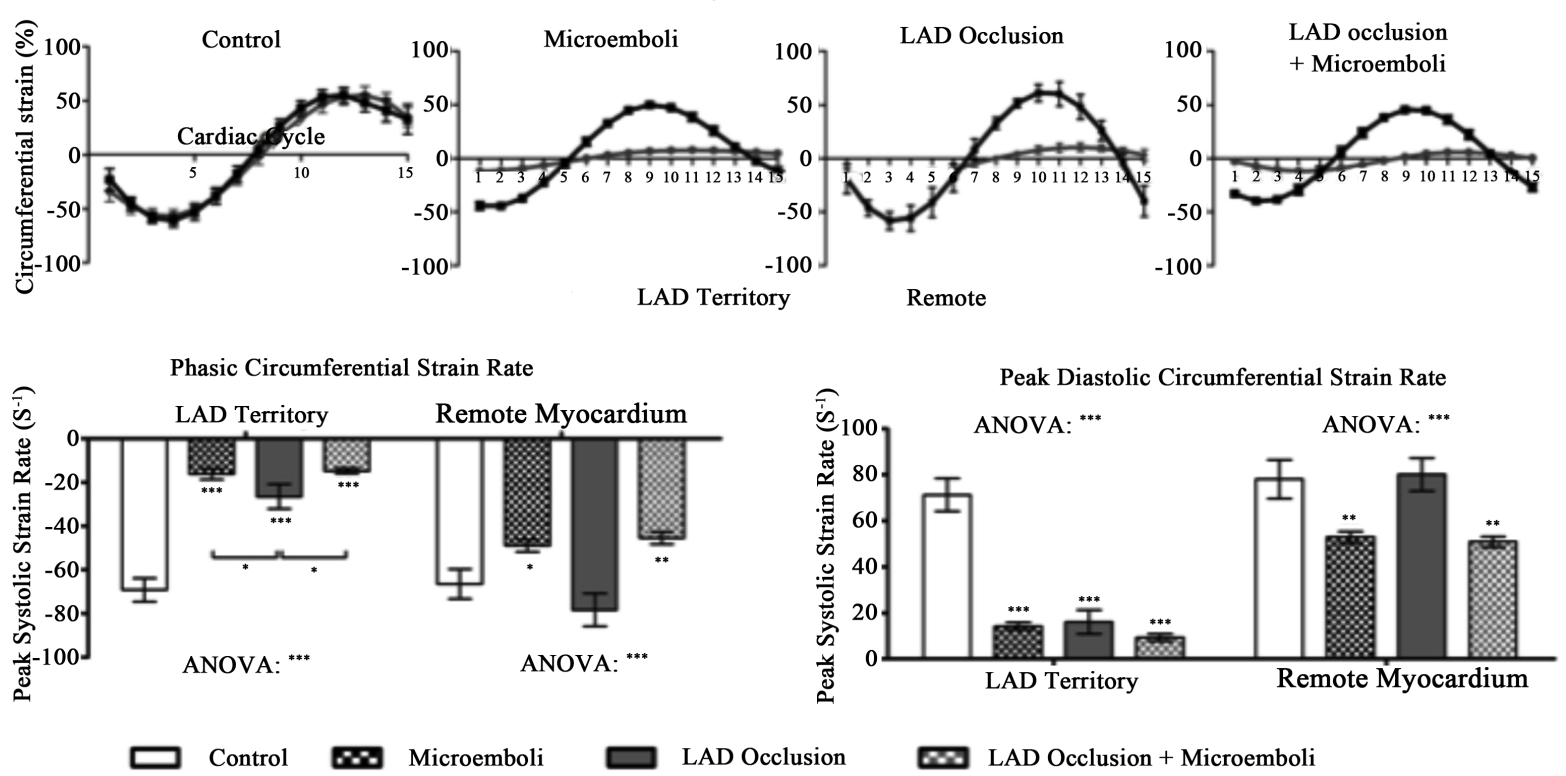

Figure 11. Top row: Circumferential strain rate curves. In control animals, remote myocardium and LAD territory have identical curves, while remote vs. LAD territory in all interventions were significantly different $(P<0.001)$. Bottom left: The LAD territory showed significantly decreased systolic strain rate in LAD territory for all interventions, with microembolized and combined groups significantly less than solely LAD occlusion. Remote myocardium showed only a decrease in microembolized and combined groups. Bottom right: The LAD territory demonstrated significantly decreased diastolic strain rate in LAD territory for all interventions. Remote myocardium again showed only significant decrease in microembolized and combined groups. ${ }^{*} P<0.05,{ }^{* *} P<0.01,{ }^{* * *} P<0.001[130]$.

creatine-kinase levels were elevated $>2$ times the upper normal range compared with patients whose creatinekinase were not elevated [73]. Such observations have been confirmed by subsequent studies [18] [73] [150] [151].

Recent clinical studies showed a link between MR visualization of microinfarction and impaired myocardial perfusion [95] [96]. Selvanayagam et al. examined myocardial perfusion and necrosis serially after PCI with a validated, quantitative MR technique [17] and found that myocardial perfusion is reduced in segments with infarct after PCI. Investigators also reported that patchy microinfarct at the peri-infarct zone might be an arrhythmogenic substrate [107] [152]-[154]. The proposed pathophysiological explanation is that the tissue heterogeneity with re-entrant ventricular tachycardia is promoted in patchy infarcts with interwoven bundles of myocytes [107] [155].

\section{Microemboli and Myocardial Protection}

The clinical impact of microemboli on patients with STEMI is evident. Distal protection devices and thrombectomy catheters are widely used to minimize coronary microembolization. These devices are positioned distal to the target lesion to filter emboli sloughed into the lumen of the artery during PCI. Depending on the pore size of these filters, they catch emboli down to a certain size of particles, while allowing continuous blood flow during the procedure. Most of these filters have a pore size of $100 \mu \mathrm{m}$ or larger, which can allow smaller particles to go to microvessels with the possibility of microinfarct. There have been considerable advances in developing distal protection devices, thrombectomy catheters and therapies for minimizing the effects of microemboli during coronary interventions [60] [74] [156]-[161]. Distal protection devices, such as the Filter Wire System, have been shown to reduce the incidence of microinfarction and adverse cardiac events in patients undergoing saphenous vein graft interventions [162]. Other investigators found that it also improve microcirculation and LV function in patients [162] [163]. Others questioned its effectiveness in filtering microemboli because cardiac complications are observed after utilization of the filters [58] [164]. The impact of these devices on myocardial perfusion and clinical outcome in patients remains limited [164]. The absence of benefits with the 
use of distal filter wire protection devices could be explained by the low sensitivity of the assay methods, the fact that such devices can themselves induce distal embolization when crossing highly thrombotic lesions or may not be effective in filtering microemboli which is related to the large pores $(\sim 120 \mu \mathrm{m})$ of these filters that allow the passage of $<120 \mu \mathrm{m}$ microemboli.

Another approach to reduce coronary microemboli is to use therapeutic drugs or anti-platelet agents. The glycoprotein IIb/IIIa inhibitors are synthetic, non-peptide inhibitor acting at glycoprotein (GP) IIb/IIIa receptors in platelets. Junghans et al. found that glycoprotein IIb/IIIa receptor antagonist tirofiban reversibly suppressed HITS (microemboli) in the cerebrovascular circulation [165]. Others found this class of therapy inhibitors MVO [166] [167]. Yang et al. found in infarction that tirofiban is very effective in improving myocardial perfusion via vascular endothelial protection [168]. These findings support the concept that endothelial protection, apart from platelet inhibition, contributes to the efficacy of tirofiban on myocardial perfusion. Despite the adverse outcomes associated with microembolization, proven targeted therapies remain elusive. The presented data that obtained from controlled studies may activate the development of new devices and therapies for preventing microembolization and treating microinfarct, respectively. MRI and MDCT are useful noninvasive techniques for guiding interventional procedures and assessing the effects of microemboli and therapies.

\section{Conclusion}

The sequellae of changes in coronary arteries and myocardium after microembolization has been documented in experimental animals and patients subjected to coronary interventions. Non-invasive imaging modalities can play important role in assessing the short- and long-term effects of coronary microemboli on cardiac function, perfusion and viability. Non-invasive imaging may also help in assessing the efficacy of newer distal filtration devices and therapies in patients.

\section{References}

[1] Go, A.S., Mozaffarian, D., Roger, V.L., et al. (2013) Heart Disease and Stroke Statistics-2013 Update: A Report from the American Heart Association. Circulation, 127, e6-e245. http://dx.doi.org/10.1161/CIR.0b013e31828124ad

[2] Khan, J.N., Razvi, N., Nazir, S.A., et al. (2014) Prevalence and Extent of Infarct and Microvascular Obstruction Following Different Reperfusion Therapies in ST-Elevation Myocardial Infarction. Journal of Cardiovascular Magnetic Resonance, 16, 38. http://dx.doi.org/10.1186/1532-429X-16-38

[3] Caraballo, V. (1997) Fatal Myocardial Infarction Resulting from Coronary Artery Septic Embolism after Abortion: Unusual Cause and Complication of Endocarditis. Annals of Emergency Medicine, 29, 175-177. http://dx.doi.org/10.1016/S0196-0644(97)70325-1

[4] Charles, R.G., Epstein, E.J., Holt, S. and Coulshed, N. (1982) Coronary Embolism in Valvular Heart Disease. Quarterly Journal of Medicine, 51, 147-161.

[5] Garg, R.K. and Jolly, N. (2007) Acute Myocardial Infarction Secondary to Thromboembolism in a Patient with Atrial Fibrillation. International Journal of Cardiology, 123, e18-e20. http://dx.doi.org/10.1016/j.ijcard.2006.11.095

[6] Kitts, D., Bongard, F.S. and Klein, S.R. (1991) Septic Embolism Complicating Infective Endocarditis. Journal of Vascular Surgery, 14, 480-485. http://dx.doi.org/10.1016/0741-5214(91)90241-L

[7] Quinn, E.G. and Fergusson, D.J. (1998) Coronary Embolism Following Aortic and Mitral Valve Replacement: Successful Management with Abciximab and Urokinase. Catheterization and Cardiovascular Diagnosis, 43, 457-459. http://dx.doi.org/10.1002/(SICI)1097-0304(199804)43:4<457::AID-CCD24>3.0.CO;2-F

[8] Takenaka, T., Horimoto, M., Igarashi, K., Yoshie, H., Tsujino, I. and Morihira, M. (1996) Multiple Coronary Thromboemboli Complicating Valvular Heart Disease and Atrial Fibrillation. American Heart Journal, 131, 194-196. http://dx.doi.org/10.1016/S0002-8703(96)90070-8

[9] Yutani, C., Imakita, M., Ueda-Ishibashi, H., Katsuragi, M. and Fujita, H. (1992) Coronary Artery Embolism with Special Reference to Invasive Procedures as the Source. Modern Pathology, 5, 244-249.

[10] Erbel, R. (2003) Spontaneous and Interventional Coronary Microembolisation. Heart, 89, 986-989. http://dx.doi.org/10.1136/heart.89.9.986

[11] Mandell, B.F. (1987) Cardiovascular Involvement in Systemic Lupus Erythematosus. Seminars in Arthritis and Rheumatism, 17, 126-141. http://dx.doi.org/10.1016/0049-0172(87)90035-7

[12] Westwood, M.A., Shah, F., Anderson, L.J., et al. (2007) Myocardial Tissue Characterization and the Role of Chronic Anemia in Sickle Cell Cardiomyopathy. Journal of Magnetic Resonance Imaging, 26, 564-568. 
http://dx.doi.org/10.1002/jmri.21018

[13] Steg, P.G., James, S.K., Atar, D., et al. (2012) ESC Guidelines for the Management of Acute Myocardial Infarction in Patients Presenting with ST-Segment Elevation. European Heart Journal, 33, 2569-2619. http://dx.doi.org/10.1093/eurheartj/ehs215

[14] Anderson, J.L., Adams, C.D., Antman, E.M., et al. (2007) ACC/AHA 2007 Guidelines for the Management of Patients with Unstable Angina/Non-ST-Elevation Myocardial Infarction: A Report of the American College of Cardiology/American Heart Association Task Force on Practice Guidelines (Writing Committee to Revise the 2002 Guidelines for the Management of Patients With Unstable Angina/Non-ST-Elevation Myocardial Infarction) Developed in Collaboration with the American College of Emergency Physicians, the Society for Cardiovascular Angiography and Interventions, and the Society of Thoracic Surgeons Endorsed by the American Association of Cardiovascular and Pulmonary Rehabilitation and the Society for Academic Emergency Medicine. Journal of the American College of Cardiology, 50, e1-e157. http://dx.doi.org/10.1016/j.jacc.2007.02.013

[15] Porto, I., Selvanayagam, J.B., Van Gaal, W.J., et al. (2006) Plaque Volume and Occurrence and Location of Periprocedural Myocardial Necrosis after Percutaneous Coronary Intervention: Insights from Delayed-Enhancement Magnetic Resonance Imaging, Thrombolysis in Myocardial Infarction Myocardial Perfusion Grade Analysis, and Intravascular Ultrasound. Circulation, 114, 662-669. http://dx.doi.org/10.1161/CIRCULATIONAHA.105.593210

[16] Falk, E. (1985) Unstable Angina with Fatal Outcome: Dynamic Coronary Thrombosis Leading to Infarction and/or Sudden Death. Autopsy Evidence of Recurrent Mural Thrombosis with Peripheral Embolization Culminating in Total Vascular Occlusion. Circulation, 71, 699-708. http://dx.doi.org/10.1161/01.CIR.71.4.699

[17] Selvanayagam, J.B., Cheng, A.S., Jerosch-Herold, M., et al. (2007) Effect of Distal Embolization on Myocardial Perfusion Reserve after Percutaneous Coronary Intervention: A Quantitative Magnetic Resonance Perfusion Study. Circulation, 116, 1458-1464. http://dx.doi.org/10.1161/CIRCULATIONAHA.106.671909

[18] Skyschally, A., Schulz, R., Erbel, R. and Heusch, G. (2002) Reduced Coronary and Inotropic Reserves with Coronary Microembolization. American Journal of Physiology-Heart and Circulatory Physiology, 282, H611-H614.

[19] Skyschally, A., Leineweber, K., Gres, P., Haude, M., Erbel, R. and Heusch, G. (2006) Coronary Microembolization. Basic Research in Cardiology, 101, 373-382. http://dx.doi.org/10.1007/s00395-006-0616-1

[20] Erbel, R. and Heusch, G. (2000) Coronary Microembolization. Journal of the American College of Cardiology, 36, 2224. http://dx.doi.org/10.1016/S0735-1097(00)00708-7

[21] Davies, M.J. and Thomas, A.C. (1985) Plaque Fissuring-The Cause of Acute Myocardial Infarction, Sudden Ischaemic Death, and Crescendo Angina. British Heart Journal, 53, 363-373. http://dx.doi.org/10.1136/hrt.53.4.363

[22] Davies, M.J., Thomas, A.C., Knapman, P.A. and Hangartner, J.R. (1986) Intramyocardial Platelet Aggregation in Patients with Unstable Angina Suffering Sudden Ischemic Cardiac Death. Circulation, 73, 418-427. http://dx.doi.org/10.1161/01.CIR.73.3.418

[23] Okamura, A., Ito, H., Iwakura, K., et al. (2007) Detection and Quantification of Embolic Particles during Percutaneous Coronary Intervention to Stable Plaque: It Correlates to Coronary Flow Dynamics and Myocardial Damage. Catheterization and Cardiovascular Interventions, 69, 425-431. http://dx.doi.org/10.1002/ccd.20971

[24] Kleinbongard, P., Bose, D., Baars, T., et al. (2011) Vasoconstrictor Potential of Coronary Aspirate from Patients Undergoing Stenting of Saphenous Vein Aortocoronary Bypass Grafts and Its Pharmacological Attenuation. Circulation Research, 108, 344-352. http://dx.doi.org/10.1161/CIRCRESAHA.110.235713

[25] Beltrami, C.A., Finato, N., Rocco, M., et al. (1994) Structural Basis of End-Stage Failure in Ischemic Cardiomyopathy in Humans. Circulation, 89, 151-163. http://dx.doi.org/10.1161/01.CIR.89.1.151

[26] Klein, C., Nekolla, S.G., Bengel, F.M., et al. (2002) Assessment of Myocardial Viability with Contrast-Enhanced Magnetic Resonance Imaging: Comparison with Positron Emission Tomography. Circulation, 105, 162-167. http://dx.doi.org/10.1161/hc0202.102123

[27] Anderson, R.E. (2000) How Many Deaths Are Due to Medical Errors? JAMA, 284, 2187.

[28] Antoniucci, D., Valenti, R., Migliorini, A., et al. (2003) Comparison of Impact of Emergency Percutaneous Revascularization on Outcome of Patients $>$ or $=75$ to Those $<75$ Years of Age with Acute Myocardial Infarction Complicated by Cardiogenic Shock. The American Journal of Cardiology, 91, 1458-1461.

[29] Bolognese, L., Carrabba, N., Parodi, G., et al. (2004) Impact of Microvascular Dysfunction on Left Ventricular Remodeling and Long-Term Clinical Outcome after Primary Coronary Angioplasty for Acute Myocardial Infarction. Circulation, 109, 1121-1126. http://dx.doi.org/10.1161/01.CIR.0000118496.44135.A7

[30] Bolognese, L., Carrabba, N., Santoro, G.M., Valenti, R., Buonamici, P. and Antoniucci, D. (2003) Angiographic Findings, Time Course of Regional and Global Left Ventricular Function, and Clinical Outcome in Diabetic Patients with Acute Myocardial Infarction Treated with Primary Percutaneous Transluminal Coronary Angioplasty. The American Journal of Cardiology, 91, 544-549. http://dx.doi.org/10.1016/S0002-9149(02)03302-7 
[31] Hardoff, R., Shefer, A., Gips, S., et al. (1990) Predicting Late Restenosis after Coronary Angioplasty by Very Early (12 to 24 h) Thallium-201 Scintigraphy: Implications with Regard to Mechanisms of Late Coronary Restenosis. Journal of the American College of Cardiology, 15, 1486-1492. http://dx.doi.org/10.1016/0735-1097(90)92815-J

[32] Jain, A., Mahmarian, J.J., Borges-Neto, S., et al. (1988) Clinical Significance of Perfusion Defects by Thallium-201 Single Photon Emission Tomography Following Oral Dipyridamole Early after Coronary Angioplasty. Journal of the American College of Cardiology, 11, 970-976. http://dx.doi.org/10.1016/S0735-1097(98)90053-5

[33] Wijns, W., Serruys, P.W., Reiber, J.H., et al. (1985) Early Detection of Restenosis after Successful Percutaneous Transluminal Coronary Angioplasty by Exercise-Redistribution Thallium Scintigraphy. The American Journal of Cardiology, 55, 357-361. http://dx.doi.org/10.1016/0002-9149(85)90375-3

[34] Wijns, W.W. and Serruys, P.W. (1985) Coronary Angioplasty in Myocardial Infarction. The American Journal of Cardiology, 56, 1004. http://dx.doi.org/10.1016/0002-9149(85)90430-8

[35] Bachmann, R., Sechtem, U., Voth, E., Schroder, J., Hopp, H.W. and Schicha, H. (1997) Dipyridamole Scintigraphy and Intravascular Ultrasound after Successful Coronary Intervention. The Journal of Nuclear Medicine, 38, 553-558.

[36] Holmes Jr., D.R. (1990) Very Early Prediction of Restenosis after Successful Coronary Angioplasty: How Early Is Early and Can We Identify It? Journal of the American College of Cardiology, 15, 265-266. http://dx.doi.org/10.1016/S0735-1097(10)80045-2

[37] Rodes-Cabau, J., Candell-Riera, J., Domingo, E., et al. (2001) Frequency and Clinical Significance of Myocardial Ischemia Detected Early after Coronary Stent Implantation. The Journal of Nuclear Medicine, 42, 1768-1772.

[38] Jaffe, R., Haim, S.B., Karkabi, B., et al. (2002) Myocardial Perfusion Abnormalities Early (12 - 24 h) after Coronary Stenting or Balloon Angioplasty: Implications Regarding Pathophysiology and Late Clinical Outcome. Cardiology, 98, 60-66. http://dx.doi.org/10.1159/000064680

[39] Nagaoka, H., Iizuka, T., Kubota, S., et al. (1998) Redistribution in Thallium-201 Myocardial Imaging Soon after Successful Coronary Stenting-Tomographic Evaluation during Coronary Hyperemia Induced by Adenosine. Japanese Circulation Journal, 62, 160-166. http://dx.doi.org/10.1253/jcj.62.160

[40] Niccoli, G., Burzotta, F., Galiuto, L. and Crea, F. (2009) Myocardial No-Reflow in Humans. Journal of the American College of Cardiology, 54, 281-292. http://dx.doi.org/10.1016/j.jacc.2009.03.054

[41] Heusch, G., Kleinbongard, P., Bose, D., et al. (2009) Coronary Microembolization: From Bedside to Bench and Back to Bedside. Circulation, 120, 1822-1836. http://dx.doi.org/10.1161/CIRCULATIONAHA.109.888784

[42] Barrabes, J.A., Garcia-Dorado, D., Mirabet, M., et al. (2005) Antagonism of Selectin Function Attenuates Microvascular Platelet Deposition and Platelet-Mediated Myocardial Injury after Transient Ischemia. Journal of the American College of Cardiology, 45, 293-299. http://dx.doi.org/10.1016/j.jacc.2004.09.068

[43] Ambrosio, G., Weisman, H.F., Mannisi, J.A. and Becker, L.C. (1989) Progressive Impairment of Regional Myocardial Perfusion after Initial Restoration of Postischemic Blood Flow. Circulation, 80, 1846-1861. http://dx.doi.org/10.1161/01.CIR.80.6.1846

[44] Jaffe, R., Dick, A. and Strauss, B.H. (2010) Prevention and Treatment of Microvascular Obstruction-Related Myocardial Injury and Coronary No-Reflow Following Percutaneous Coronary Intervention: A Systematic Approach. JACC: Cardiovascular Interventions, 3, 695-704. http://dx.doi.org/10.1016/j.jcin.2010.05.004

[45] Monassier, J.P. (2008) Reperfusion Injury in Acute Myocardial Infarction: From Bench to Cath Lab. Part II: Clinical Issues and Therapeutic Options. Archives of Cardiovascular Diseases, 101, 565-575. http://dx.doi.org/10.1016/j.acvd.2008.06.013

[46] Niccoli, G., Cosentino, N., Spaziani, C., Minelli, S., Fracassi, F. and Crea, F. (2011) New Strategies for the Management of No-Reflow after Primary Percutaneous Coronary Intervention. Expert Review of Cardiovascular Therapy, 9, 615-630. http://dx.doi.org/10.1586/erc.11.49

[47] Porto, I., Biasucci, L.M., De Maria, G.L., et al. (2012) Intracoronary Microparticles and Microvascular Obstruction in Patients with ST Elevation Myocardial Infarction Undergoing Primary Percutaneous Intervention. European Heart Journal, 33, 2928-2938. http://dx.doi.org/10.1093/eurheartj/ehs065

[48] Califf, R.M., Abdelmeguid, A.E., Kuntz, R.E., et al. (1998) Myonecrosis after Revascularization Procedures. Journal of the American College of Cardiology, 31, 241-251. http://dx.doi.org/10.1016/S0735-1097(97)00506-8

[49] Herrmann, J. (2005) Peri-Procedural Myocardial Injury: 2005 Update. European Heart Journal, 26, $2493-2519$. http://dx.doi.org/10.1093/eurheartj/ehi455

[50] Chia, S., Senatore, F., Raffel, O.C., Lee, H., Wackers, F.J. and Jang, I.K. (2008) Utility of Cardiac Biomarkers in Predicting Infarct Size, Left Ventricular Function, and Clinical Outcome after Primary Percutaneous Coronary Intervention for ST-Segment Elevation Myocardial Infarction. JACC: Cardiovascular Interventions, 1, 415-423. http://dx.doi.org/10.1016/j.jcin.2008.04.010 
[51] Hallen, J., Buser, P., Schwitter, J., et al. (2009) Relation of Cardiac Troponin I Measurements at 24 and 48 Hours to Magnetic Resonance-Determined Infarct Size in Patients with ST-Elevation Myocardial Infarction. The American Journal of Cardiology, 104, 1472-1477. http://dx.doi.org/10.1016/j.amjcard.2009.07.019

[52] Giannitsis, E., Steen, H., Kurz, K., et al. (2008) Cardiac Magnetic Resonance Imaging Study for Quantification of Infarct Size Comparing Directly Serial versus Single Time-Point Measurements of Cardiac Troponin T. Journal of the American College of Cardiology, 51, 307-314. http://dx.doi.org/10.1016/j.jacc.2007.09.041

[53] Saeed, M., Hetts, S.W., Do, L. and Wilson, M.W. (2013) MRI Study on Volume Effects of Coronary Emboli on Myocardial Function, Perfusion and Viability. International Journal of Cardiology, 165, 93-99. http://dx.doi.org/10.1016/j.ijcard.2011.07.096

[54] Saeed, M., Hetts, S.W., Do, L. and Wilson, M.W. (2013) Coronary Microemboli Effects in Preexisting Acute Infarcts in a Swine Model: Cardiac MR Imaging Indices, Injury Biomarkers, and Histopathologic Assessment. Radiology, 268, 98-108. http://dx.doi.org/10.1148/radiol.13122286

[55] Mehran, R., Dangas, G., Mintz, G.S., et al. (2000) Treatment of In-Stent Restenosis with Excimer Laser Coronary Angioplasty versus Rotational Atherectomy: Comparative Mechanisms and Results. Circulation, 101, 2484-2489. http://dx.doi.org/10.1161/01.CIR.101.21.2484

[56] Kong, T.Q., Davidson, C.J., Meyers, S.N., Tauke, J.T., Parker, M.A. and Bonow, R.O. (1997) Prognostic Implication of Creatine Kinase Elevation Following Elective Coronary Artery Interventions. JAMA, 277, 461-466. http://dx.doi.org/10.1001/jama.1997.03540300029029

[57] Migliorini, A., Stabile, A., Rodriguez, A.E., et al. (2010) Comparison of AngioJet Rheolytic Thrombectomy before Direct Infarct Artery Stenting with Direct Stenting Alone in Patients with Acute Myocardial Infarction. The JETSTENT Trial. Journal of the American College of Cardiology, 56, 1298-1306. http://dx.doi.org/10.1016/j.jacc.2010.06.011

[58] Kunadian, B., Dunning, J., Vijayalakshmi, K., Thornley, A.R. and de Belder, M.A. (2007) Meta-Analysis of Randomized Trials Comparing Anti-Embolic Devices with Standard PCI for Improving Myocardial Reperfusion in Patients with Acute Myocardial Infarction. Catheterization and Cardiovascular Interventions, 69, 488-496. http://dx.doi.org/10.1002/ccd.20990

[59] Jacquier, A., Revel, D. and Saeed, M. (2008) MDCT of the Myocardium: A New Contribution to Ischemic Heart Disease. Academic Radiology, 15, 477-487. http://dx.doi.org/10.1016/j.acra.2007.11.004

[60] Okamura, A., Ito, H., Iwakura, K., et al. (2005) Detection of Embolic Particles with the Doppler Guide Wire during Coronary Intervention in Patients with Acute Myocardial Infarction: Efficacy of Distal Protection Device. Journal of the American College of Cardiology, 45, 212-215. http://dx.doi.org/10.1016/j.jacc.2004.09.062

[61] Schwartz, R.S., Burke, A., Farb, A., et al. (2009) Microemboli and Microvascular Obstruction in Acute Coronary Thrombosis and Sudden Coronary Death: Relation to Epicardial Plaque Histopathology. Journal of the American College of Cardiology, 54, 2167-2173. http://dx.doi.org/10.1016/j.jacc.2009.07.042

[62] De Maria, G.L., Patel, N., Kassimis, G. and Banning, A.P. (2013) Spontaneous and Procedural Plaque Embolisation in Native Coronary Arteries: Pathophysiology, Diagnosis, and Prevention. Scientifica (Cairo), 2013, Article ID: 364247.

[63] Falk, E. (1991) Coronary Thrombosis: Pathogenesis and Clinical Manifestations. The American Journal of Cardiology, 68, 28B-35B. http://dx.doi.org/10.1016/0002-9149(91)90382-U

[64] Furie, B. and Furie, B.C. (2008) Mechanisms of Thrombus Formation. The New England Journal of Medicine, 359, 938-949. http://dx.doi.org/10.1056/NEJMra0801082

[65] Bose, D., von Birgelen, C., Zhou, X.Y., et al. (2008) Impact of Atherosclerotic Plaque Composition on Coronary Microembolization during Percutaneous Coronary Interventions. Basic Research in Cardiology, 103, 587-597. http://dx.doi.org/10.1007/s00395-008-0745-9

[66] Hong, Y.J., Mintz, G.S., Kim, S.W., et al. (2009) Impact of Plaque Composition on Cardiac Troponin Elevation after Percutaneous Coronary Intervention: An Ultrasound Analysis. JACC: Cardiovascular Imaging, 2, 458-468. http://dx.doi.org/10.1016/j.jcmg.2008.12.020

[67] Uetani, T., Amano, T., Ando, H., et al. (2008) The Correlation between Lipid Volume in the Target Lesion, Measured by Integrated Backscatter Intravascular Ultrasound, and Post-Procedural Myocardial Infarction in Patients with Elective Stent Implantation. European Heart Journal, 29, 1714-1720. http://dx.doi.org/10.1093/eurheartj/ehn248

[68] Gu, Y., Bai, Y., Wu, J., Hu, L. and Gao, B. (2010) Establishment and Characterization of an Experimental Model of Coronary Thrombotic Microembolism in Rats. The American Journal of Pathology, 177, 1122-1130. http://dx.doi.org/10.2353/ajpath.2010.090889

[69] Dicks DL, Carlsson M, Heiberg E, et al. (2009) Persistent Decline in Longitudinal and Radial Strain after Coronary Microembolization Detected on Velocity Encoded Phase Contrast Magnetic Resonance Imaging. Journal of Magnetic Resonance Imaging, 30, 69-76. http://dx.doi.org/10.1002/jmri.21773

[70] Carlsson, M., Wilson, M., Martin, A.J. and Saeed, M. (2009) Myocardial Microinfarction after Coronary Microembo- 
lization in Swine: MR Imaging Characterization. Radiology, 250, 703-713.

http://dx.doi.org/10.1148/radiol.2503081000

[71] Carlsson, M., Saloner, D., Martin, A.J., Ursell, P.C. and Saeed, M. (2010) Heterogeneous Microinfarcts Caused by Coronary Microemboli: Evaluation with Multidetector CT and MR Imaging in a Swine Model. Radiology, 254, 718728. http://dx.doi.org/10.1148/radiol.09090527

[72] Carlsson, M., Martin, A.J., Ursell, P.C., Saloner, D. and Saeed, M. (2009) Magnetic Resonance Imaging Quantification of Left Ventricular Dysfunction Following Coronary Microembolization. Magnetic Resonance in Medicine, 61, 595602. http://dx.doi.org/10.1002/mrm.21869

[73] Dorge, H., Neumann, T., Behrends, M., et al. (2000) Perfusion-Contraction Mismatch with Coronary Microvascular Obstruction: Role of Inflammation. American Journal of Physiology-Heart and Circulatory Physiology, 279, H2587H2592.

[74] Angelini, A., Rubartelli, P., Mistrorigo, F., et al. (2004) Distal Protection with a Filter Device during Coronary Stenting in Patients with Stable and Unstable Angina. Circulation, 110, 515-521. http://dx.doi.org/10.1161/01.CIR.0000137821.94074.EE

[75] Bahrmann, P., Figulla, H.R., Wagner, M., Ferrari, M., Voss, A. and Werner, G.S. (2005) Detection of Coronary Microembolisation by Doppler Ultrasound during Percutaneous Coronary Interventions. Heart, 91, 1186-1192. http://dx.doi.org/10.1136/hrt.2004.048629

[76] Bahrmann, P., Werner, G.S., Heusch, G., et al. (2007) Detection of Coronary Microembolization by Doppler Ultrasound in Patients with Stable Angina Pectoris Undergoing Elective Percutaneous Coronary Interventions. Circulation, 115, 600-608. http://dx.doi.org/10.1161/CIRCULATIONAHA.106.660779

[77] DeMaria, A.N., Narula, J., Mahmud, E. and Tsimikas, S. (2006) Imaging Vulnerable Plaque by Ultrasound. Journal of the American College of Cardiology, 47, C32-C39. http://dx.doi.org/10.1016/j.jacc.2005.11.047

[78] Fujii, K., Carlier, S.G., Mintz, G.S., et al. (2005) Association of Plaque Characterization by Intravascular Ultrasound Virtual Histology and Arterial Remodeling. The American Journal of Cardiology, 96, 1476-1483. http://dx.doi.org/10.1016/j.amjcard.2005.07.054

[79] Nair, A., Kuban, B.D., Tuzcu, E.M., Schoenhagen, P., Nissen, S.E. and Vince, D.G. (2002) Coronary Plaque Classification with Intravascular Ultrasound Radiofrequency Data Analysis. Circulation, 106, 2200-2206. http://dx.doi.org/10.1161/01.CIR.0000035654.18341.5E

[80] Rodriguez-Granillo, G.A., Serruys, P.W., Garcia-Garcia, H.M., et al. (2006) Coronary Artery Remodelling Is Related to Plaque Composition. Heart, 92, 388-391. http://dx.doi.org/10.1136/hrt.2004.057810

[81] Vancraeynest, D., Pasquet, A., Roelants, V., Gerber, B.L. and Vanoverschelde, J.L. (2011) Imaging the Vulnerable Plaque. Journal of the American College of Cardiology, 57, 1961-1979. http://dx.doi.org/10.1016/j.jacc.2011.02.018

[82] Freeman, M.R., Williams, A.E., Chisholm, R.J. and Armstrong, P.W. (1989) Intracoronary Thrombus and Complex Morphology in Unstable Angina. Relation to Timing of Angiography and In-Hospital Cardiac Events. Circulation, 80, 17-23. http://dx.doi.org/10.1161/01.CIR.80.1.17

[83] Kirma, C., Izgi, A., Dundar, C., et al. (2008) Clinical and Procedural Predictors of No-Reflow Phenomenon after Primary Percutaneous Coronary Interventions: Experience at a Single Center. Circulation Journal, 72, 716-721. http://dx.doi.org/10.1253/circj.72.716

[84] Napodano, M., Pasquetto, G., Sacca, S., et al. (2003) Intracoronary Thrombectomy Improves Myocardial Reperfusion in Patients Undergoing Direct Angioplasty for Acute Myocardial Infarction. Journal of the American College of Cardiology, 42, 1395-1402. http://dx.doi.org/10.1016/S0735-1097(03)01041-6

[85] Zhao, X.Q., Theroux, P., Snapinn, S.M. and Sax, F.L. (1999) Intracoronary Thrombus and Platelet Glycoprotein IIb/IIIa Receptor Blockade with Tirofiban in Unstable Angina or Non-Q-Wave Myocardial Infarction. Angiographic Results from the PRISM-PLUS Trial (Platelet Receptor Inhibition for Ischemic Syndrome Management in Patients Limited by Unstable Signs and Symptoms). PRISM-PLUS Investigators. Circulation, 100, 1609-1615. http://dx.doi.org/10.1161/01.CIR.100.15.1609

[86] Chechi, T., Vecchio, S., Vittori, G., et al. (2008) ST-Segment Elevation Myocardial Infarction Due to Early and Late Stent Thrombosis a New Group of High-Risk Patients. Journal of the American College of Cardiology, 51, $2396-2402$. http://dx.doi.org/10.1016/j.jacc.2008.01.070

[87] Carlsson, M., Osman, N.F., Ursell, P.C., Martin, A.J. and Saeed, M. (2008) Quantitative MR Measurements of Regional and Global Left Ventricular Function and Strain after Intramyocardial Transfer of VM202 into Infarcted Swine Myocardium. American Journal of Physiology-Heart and Circulatory Physiology, 295, H522-H532. http://dx.doi.org/10.1152/ajpheart.00280.2008

[88] Dicks, D., Saloner, D., Martin, A., Ursell, P., Carlsson, M. and Saeed, M. (2009) Cardiovascular Magnetic Resonance Imaging for Percutaneous Transendocardial Delivery and Three Dimensional Left Ventricular Strain Assessment of 
VEGF Gene Therapy in Occlusive Infarction. International Journal of Cardiology, 143, 255-263. http://dx.doi.org/10.1016/j.ijcard.2009.02.030

[89] Jacquier, A., Higgins, C.B., Martin, A.J., Do, L., Saloner, D. and Saeed, M. (2007) Injection of Adeno-Associated Viral Vector Encoding Vascular Endothelial Growth Factor Gene in Infarcted Swine Myocardium: MR Measurements of Left Ventricular Function and Strain. Radiology, 245, 196-205. http://dx.doi.org/10.1148/radiol.2451061077

[90] Saeed, M., Martin, A., Jacquier, A., et al. (2008) Permanent Coronary Artery Occlusion: Cardiovascular MR Imaging Is Platform for Percutaneous Transendocardial Delivery and Assessment of Gene Therapy in Canine Model. Radiology, 249, 560-571. http://dx.doi.org/10.1148/radiol.2491072068

[91] Saeed, M., Martin, A., Ursell, P., et al. (2008) MR assessment of Myocardial Perfusion, Viability, and Function after Intramyocardial Transfer of VM202, a New Plasmid Human Hepatocyte Growth Factor in Ischemic Swine Myocardium. Radiology, 249, 107-118. http://dx.doi.org/10.1148/radiol.2483071579

[92] Saeed, M., Saloner, D., Martin, A., et al. (2007) Adeno-Associated Viral Vector-Encoding Vascular Endothelial Growth Factor Gene: Effect on Cardiovascular MR Perfusion and Infarct Resorption Measurements in Swine. Radiology, 243, 451-460. http://dx.doi.org/10.1148/radiol.2432060928

[93] Saeed, M., Weber, O., Lee, R., et al. (2006) Discrimination of Myocardial Acute and Chronic (Scar) Infarctions on Delayed Contrast Enhanced Magnetic Resonance Imaging with Intravascular Magnetic Resonance Contrast Media. Journal of the American College of Cardiology, 48, 1961-1968. http://dx.doi.org/10.1016/j.jacc.2006.03.071

[94] Saeed, M., Martin, A.J., Lee, R.J., et al. (2006) MR Guidance of Targeted Injections into Border and Core of Scarred Myocardium in Pigs. Radiology, 240, 419-426. http://dx.doi.org/10.1148/radiol.2402051086

[95] Choi, J.W., Gibson, C.M., Murphy, S.A., Davidson, C.J., Kim, R.J. and Ricciardi, M.J. (2004) Myonecrosis Following Stent Placement: Association between Impaired TIMI Myocardial Perfusion Grade and MRI Visualization of Microinfarction. Catheterization and Cardiovascular Interventions, 61, 472-476. http://dx.doi.org/10.1002/ccd.20024

[96] Ricciardi, M.J., Wu, E., Davidson, C.J., et al. (2001) Visualization of Discrete Microinfarction after Percutaneous Coronary Intervention Associated with Mild Creatine Kinase-MB Elevation. Circulation, 103, 2780-2783. http://dx.doi.org/10.1161/hc2301.092121

[97] Selvanayagam, J.B., Kardos, A., Nicolson, D., et al. (2004) Anteroseptal or Apical Myocardial Infarction: A Controversy Addressed Using Delayed Enhancement Cardiovascular Magnetic Resonance Imaging. Journal of Cardiovascular Magnetic Resonance, 6, 653-661. http://dx.doi.org/10.1081/JCMR-120038647

[98] Selvanayagam, J.B., Petersen, S.E., Francis, J.M., et al. (2004) Effects of Off-Pump versus On-Pump Coronary Surgery on Reversible and Irreversible Myocardial Injury: A Randomized Trial Using Cardiovascular Magnetic Resonance Imaging and Biochemical Markers. Circulation, 109, 345-350. http://dx.doi.org/10.1161/01.CIR.0000109489.71945.BD

[99] Saeed, M., Hetts, S., English, J., Do, L. and Wilson, M. (2011) Quantitative and Qualitative Characterization of the Acute Changes in Myocardial Structure and Function after Distal Coronary Microembolization Using MDCT. Academic Radiology, 18, 479-87. http://dx.doi.org/10.1016/j.acra.2010.11.016

[100] George, R.T., Jerosch-Herold, M., Silva, C., et al. (2007) Quantification of Myocardial Perfusion Using Dynamic 64-Detector Computed Tomography. Investigative Radiology, 42, 815-822. http://dx.doi.org/10.1097/RLI.0b013e318124a884

[101] Galiuto, L. (2004) Optimal Therapeutic Strategies in the Setting of Post-Infarct No Reflow: The Need for a Pathogenetic Classification. Heart, 90, 123-125. http://dx.doi.org/10.1136/hrt.2003.020800

[102] Breuckmann, F., Nassenstein, K., Bucher, C., et al. (2009) Systematic Analysis of Functional and Structural Changes after Coronary Microembolization: A Cardiac Magnetic Resonance Imaging Study. JACC: Cardiovascular Imaging, 2, 121-130. http://dx.doi.org/10.1016/j.jcmg.2008.10.011

[103] Nassenstein, K., Breuckmann, F., Bucher, C., et al. (2008) How Much Myocardial Damage Is Necessary to Enable Detection of Focal Late Gadolinium Enhancement at Cardiac MR Imaging? Radiology, 249, 829-835. http://dx.doi.org/10.1148/radiol.2493080457

[104] Saeed, M., Hetts, S.W., Do, L., Sullivan, S. and Wilson, M.W. (2012) MDCT Has the Potential to Predict Percutaneous Coronary Intervention Outcome in Swine Model: Microscopic Validation. Acta Radiologica, 53, 987-994. http://dx.doi.org/10.1258/ar.2012.120407

[105] Saeed, M., Hetts, S.W., Ursell, P.C., Do, L., Kolli, K.P. and Wilson, M.W. (2012) Evaluation of the Acute Effects of Distal Coronary Microembolization Using Multidetector Computed Tomography and Magnetic Resonance Imaging. Magnetic Resonance in Medicine, 67, 1747-1757. http://dx.doi.org/10.1002/mrm.23149

[106] Robbers, L.F., Delewi, R., Nijveldt, R., et al. (2013) Myocardial Infarct Heterogeneity Assessment by Late Gadolinium Enhancement Cardiovascular Magnetic Resonance Imaging Shows Predictive Value for Ventricular Arrhythmia Development after Acute Myocardial Infarction. European Heart Journal-Cardiovascular Imaging, 14, 1150-1158. 
http://dx.doi.org/10.1093/ehjci/jet111

[107] Yan, A.T., Shayne, A.J., Brown, K.A., et al. (2006) Characterization of the Peri-Infarct Zone by Contrast-Enhanced Cardiac Magnetic Resonance Imaging Is a Powerful Predictor of Post-Myocardial Infarction Mortality. Circulation, 114, 32-39. http://dx.doi.org/10.1161/CIRCULATIONAHA.106.613414

[108] Kramer, C.M., Rogers, W.J., Park, C.S., et al. (1998) Regional Myocyte Hypertrophy Parallels Regional Myocardial Dysfunction during Post-Infarct Remodeling. Journal of Molecular and Cellular Cardiology, 30, 1773-1778. http://dx.doi.org/10.1006/jmcc.1998.0741

[109] Uren, N.G., Crake, T., Lefroy, D.C., de Silva, R., Davies, G.J. and Maseri, A. (1994) Reduced Coronary Vasodilator Function in Infarcted and Normal Myocardium after Myocardial Infarction. The New England Journal of Medicine, 331, 222-227. http://dx.doi.org/10.1056/NEJM199407283310402

[110] Bogaert, J., Kalantzi, M., Rademakers, F.E., Dymarkowski, S. and Janssens, S. (2007) Determinants and Impact of Microvascular Obstruction in Successfully Reperfused ST-Segment Elevation Myocardial Infarction. Assessment by Magnetic Resonance Imaging. European Radiology, 17, 2572-2580. http://dx.doi.org/10.1007/s00330-007-0627-9

[111] Inauen, W., Payne, D.K., Kvietys, P.R. and Granger, D.N. (1990) Hypoxia/Reoxygenation Increases the Permeability of Endothelial Cell Monolayers: Role of Oxygen Radicals. Free Radical Biology \& Medicine, 9, 219-223. http://dx.doi.org/10.1016/0891-5849(90)90031-D

[112] Choi, C.J., Haji-Momenian, S., Dimaria, J.M., et al. (2004) Infarct Involution and Improved Function during Healing of Acute Myocardial Infarction: The Role of Microvascular Obstruction. Journal of Cardiovascular Magnetic Resonance, 6, 917-925. http://dx.doi.org/10.1081/JCMR-200036206

[113] Ingkanisorn, W.P., Rhoads, K.L., Aletras, A.H., Kellman, P. and Arai, A.E. (2004) Gadolinium Delayed Enhancement Cardiovascular Magnetic Resonance Correlates with Clinical Measures of Myocardial Infarction. Journal of the American College of Cardiology, 43, 2253-2259. http://dx.doi.org/10.1016/j.jacc.2004.02.046

[114] Hombach, V., Grebe, O., Merkle, N., et al. (2005) Sequelae of Acute Myocardial Infarction Regarding Cardiac Structure and Function and Their Prognostic Significance as Assessed by Magnetic Resonance Imaging. European Heart Journal, 26, 549-557. http://dx.doi.org/10.1093/eurheartj/ehi147

[115] Ibrahim, T., Hackl, T., Nekolla, S.G., et al. (2010) Acute Myocardial Infarction: Serial Cardiac MR Imaging Shows a Decrease in Delayed Enhancement of the Myocardium during the 1st Week after Reperfusion. Radiology, 254, 88-97. http://dx.doi.org/10.1148/radiol.09090660

[116] Mather, A.N., Fairbairn, T.A., Artis, N.J., Greenwood, J.P. and Plein, S. (2011) Timing of Cardiovascular MR Imaging after Acute Myocardial Infarction: Effect on Estimates of Infarct Characteristics and Prediction of Late Ventricular Remodeling. Radiology, 261, 116-126. http://dx.doi.org/10.1148/radiol.11110228

[117] Ghugre, N.R., Pop, M., Barry, J., Connelly, K.A. and Wright, G.A. (2013) Quantitative Magnetic Resonance Imaging Can Distinguish Remodeling Mechanisms after Acute Myocardial Infarction Based on the Severity of Ischemic Insult. Magnetic Resonance in Medicine, 70, 1095-1105. http://dx.doi.org/10.1002/mrm.24531

[118] Bajwa, H.Z., Do, L., Suhail, M., Hetts, S.W., Wilson, M.W. and Saeed, M. (2014) MRI Demonstrates a Decrease in Myocardial Infarct Healing and Increase in Compensatory Ventricular Hypertrophy Following Mechanical Microvascular Obstruction. Journal of Magnetic Resonance Imaging, 40, 906-914. http://dx.doi.org/10.1002/jmri.24431

[119] Kloner, R.A., Rude, R.E., Carlson, N., Maroko, P.R., DeBoer, L.W. and Braunwald, E. (1980) Ultrastructural Evidence of Microvascular Damage and Myocardial Cell Injury after Coronary Artery Occlusion: Which Comes First? Circulation, 62, 945-952. http://dx.doi.org/10.1161/01.CIR.62.5.945

[120] Wu, K.C., Zerhouni, E.A., Judd, R.M., et al. (1998) Prognostic Significance of Microvascular Obstruction by Magnetic Resonance Imaging in Patients with Acute Myocardial Infarction. Circulation, 97, 765-772. http://dx.doi.org/10.1161/01.CIR.97.8.765

[121] Klem, I., Shah, D.J., White, R.D., et al. (2011) Prognostic Value of Routine Cardiac Magnetic Resonance Assessment of Left Ventricular Ejection Fraction and Myocardial Damage: An International, Multicenter Study. Circulation: Cardiovascular Imaging, 4, 610-619. http://dx.doi.org/10.1161/CIRCIMAGING.111.964965

[122] Wu, E., Ortiz, J.T., Tejedor, P., et al. (2008) Infarct Size by Contrast Enhanced Cardiac Magnetic Resonance Is a Stronger Predictor of Outcomes than Left Ventricular Ejection Fraction or End-Systolic Volume Index: Prospective Cohort Study. Heart, 94, 730-736. http://dx.doi.org/10.1136/hrt.2007.122622

[123] De Waha, S., Desch, S., Eitel, I., et al. (2010) Impact of Early vs. Late Microvascular Obstruction Assessed by Magnetic Resonance Imaging on Long-Term Outcome after ST-Elevation Myocardial Infarction: A Comparison with Traditional Prognostic Markers. European Heart Journal, 31, 2660-2668. http://dx.doi.org/10.1093/eurheartj/ehq247

[124] Klug, G., Mayr, A., Schenk, S., et al. (2012) Prognostic Value at 5 Years of Microvascular Obstruction after Acute Myocardial Infarction Assessed by Cardiovascular Magnetic Resonance. Journal of Cardiovascular Magnetic Resonance, 14, 46. http://dx.doi.org/10.1186/1532-429X-14-46 
[125] Rezkalla, S.H. and Kloner, R.A. (2008) Coronary No-Reflow Phenomenon: From the Experimental Laboratory to the Cardiac Catheterization Laboratory. Catheterization and Cardiovascular Interventions, 72, 950-957. http://dx.doi.org/10.1002/ccd.21715

[126] Lund, G.K., Stork, A., Saeed, M., et al. (2004) Acute Myocardial Infarction: Evaluation with First-Pass Enhancement and Delayed Enhancement MR Imaging Compared with 201Tl SPECT Imaging. Radiology, 232, 49-57. http://dx.doi.org/10.1148/radiol.2321031127

[127] Hori, M., Inoue, M., Kitakaze, M., et al. (1986) Role of Adenosine in Hyperemic Response of Coronary Blood Flow in Microembolization. American Journal of Physiology, 250, H509-H518.

[128] Dorge, H., Schulz, R., Belosjorow, S., et al. (2002) Coronary Microembolization: The Role of TNF-Alpha in Contractile Dysfunction. Journal of Molecular and Cellular Cardiology, 34, 51-62. http://dx.doi.org/10.1006/jmcc.2001.1489

[129] Pfeffer, M.A., Pfeffer, J.M., Fishbein, M.C., et al. (1979) Myocardial Infarct Size and Ventricular Function in Rats. Circulation Research, 44, 503-512. http://dx.doi.org/10.1161/01.RES.44.4.503

[130] Suhail, M.S., Wilson, M.W., Hetts, S.W. and Saeed, M. (2013) Magnetic Resonance Imaging Characterization of Circumferential and Longitudinal Strain under Various Coronary Interventions in Swine. World Journal of Radiology, 5, 472-483. http://dx.doi.org/10.4329/wjr.v5.i12.472

[131] Pfeffer, M.A. (1995) Left Ventricular Remodeling after Acute Myocardial Infarction. Annual Review of Medicine, 46, 455-466. http://dx.doi.org/10.1146/annurev.med.46.1.455

[132] Ingels Jr., N.B., Daughters 2nd, G.T., Stinson, E.B. and Alderman, E.L. (1975) Measurement of Midwall Myocardial Dynamics in Intact Man by Radiography of Surgically Implanted Markers. Circulation, 52, 859-867. http://dx.doi.org/10.1161/01.CIR.52.5.859

[133] Ingels Jr., NB., Daughters 2nd, G.T., Stinson, E.B. and Alderman, E.L. (1980) Evaluation of Methods for Quantitating Left Ventricular Segmental Wall Motion in Man Using Myocardial Markers as a Standard. Circulation, 61, 966-972. http://dx.doi.org/10.1161/01.CIR.61.5.966

[134] Ordovas, K.G., Carlsson, M., Lease, K.E., et al. (2012) Impaired Regional Left Ventricular Strain after Repair of Tetralogy of Fallot. Journal of Magnetic Resonance Imaging, 35, 79-85. http://dx.doi.org/10.1002/jmri.22686

[135] Heusch, G., Schulz, R., Haude, M. and Erbel, R. (2004) Coronary Microembolization. Journal of Molecular and Cellular Cardiology, 37, 23-31. http://dx.doi.org/10.1016/j.yjmcc.2004.04.011

[136] Skyschally, A., Gres, P., Hoffmann, S., et al. (2007) Bidirectional Role of Tumor Necrosis Factor-Alpha in Coronary Microembolization: Progressive Contractile Dysfunction versus Delayed Protection against Infarction. Circulation Research, 100, 140-146. http://dx.doi.org/10.1161/01.RES.0000255031.15793.86

[137] Thielmann, M., Dorge, H., Martin, C., et al. (2002) Myocardial Dysfunction with Coronary Microembolization: Signal Transduction through a Sequence of Nitric Oxide, Tumor Necrosis Factor-Alpha, and Sphingosine. Circulation Research, 90, 807-813. http://dx.doi.org/10.1161/01.RES.0000014451.75415.36

[138] Kotani, J., Mintz, G.S., Pregowski, J., et al. (2003) Volumetric Intravascular Ultrasound Evidence That Distal Embolization during Acute Infarct Intervention Contributes to Inadequate Myocardial Perfusion Grade. The American Journal of Cardiology, 92, 728-732. http://dx.doi.org/10.1016/S0002-9149(03)00840-3

[139] Fukuda, D., Tanaka, A., Shimada, K., Nishida, Y., Kawarabayashi, T. and Yoshikawa, J. (2003) Predicting Angiographic Distal Embolization Following Percutaneous Coronary Intervention in Patients with Acute Myocardial Infarction. The American Journal of Cardiology, 91, 403-407. http://dx.doi.org/10.1016/S0002-9149(02)03233-2

[140] Frink, R.J., Rooney Jr., P.A., Trowbridge, J.O. and Rose, J.P. (1988) Coronary Thrombosis and Platelet/Fibrin Microemboli in Death Associated with Acute Myocardial Infarction. British Heart Journal, 59, 196-200. http://dx.doi.org/10.1136/hrt.59.2.196

[141] Stone, G.W., Webb, J., Cox, D.A., et al. (2005) Distal Microcirculatory Protection during Percutaneous Coronary Intervention in Acute ST-Segment Elevation Myocardial Infarction: A Randomized Controlled Trial. JAMA, 293, 10631072. http://dx.doi.org/10.1001/jama.293.9.1063

[142] Jung, C., Sorensson, P., Saleh, N., Arheden, H., Ryden, L. and Pernow, J. (2012) Circulating Endothelial and Platelet Derived Microparticles Reflect the Size of Myocardium at Risk in Patients with ST-elevation Myocardial Infarction. Atherosclerosis, 221, 226-231. http://dx.doi.org/10.1016/j.atherosclerosis.2011.12.025

[143] Saber, R.S., Edwards, W.D., Bailey, K.R., McGovern, T.W., Schwartz, R.S. and Holmes Jr., D.R. (1993) Coronary Embolization after Balloon Angioplasty or Thrombolytic Therapy: An Autopsy Study of 32 Cases. Journal of the American College of Cardiology, 22, 1283-1288. http://dx.doi.org/10.1016/0735-1097(93)90531-5

[144] Selvanayagam, J.B., Porto, I., Channon, K., et al. (2005) Troponin Elevation after Percutaneous Coronary Intervention Directly Represents the Extent of Irreversible Myocardial Injury: Insights from Cardiovascular Magnetic Resonance Imaging. Circulation, 111, 1027-1032. http://dx.doi.org/10.1161/01.CIR.0000156328.28485.AD

[145] Selvangyagam, J.B., Rahimi, K., Banning, A., et al. (2008) Prognostic Significance of Post-Procedural Irreversible 
Myocardial Injury Detected by Cardiovascular Magnetic Resonance Imaging. Journal of Cardiovascular Magnetic Resonance, 10, A1. http://dx.doi.org/10.1186/1532-429X-10-S1-A1

[146] Kotani, J., Nanto, S., Mintz, G.S., et al. (2002) Plaque Gruel of Atheromatous Coronary Lesion May Contribute to the No-Reflow Phenomenon in Patients with Acute Coronary Syndrome. Circulation, 106, 1672-1677. http://dx.doi.org/10.1161/01.CIR.0000030189.27175.4E

[147] Prati, F., Pawlowski, T., Gil, R., et al. (2003) Stenting of Culprit Lesions in Unstable Angina Leads to a Marked Reduction in Plaque Burden: A Major Role of Plaque Embolization? A Serial Intravascular Ultrasound Study. Circulation, 107, 2320-2325. http://dx.doi.org/10.1161/01.CIR.0000066695.24697.07

[148] Angioplasty Substudy Investigators (1997) A Clinical Trial Comparing Primary Coronary Angioplasty with Tissue Plasminogen Activator for Acute Myocardial Infarction. The Global Use of Strategies to Open Occluded Coronary Arteries in Acute Coronary Syndromes (GUSTO IIb) Angioplasty Substudy Investigators. The New England Journal of Medicine, 336, 1621-1628. http://dx.doi.org/10.1056/NEJM199706053362301

[149] Murakami, M., Iwasaki, K., Kusachi, S., et al. (2006) Nicorandil Reduces the Incidence of Minor Cardiac Marker Elevation after Coronary Stenting. International Journal of Cardiology, 107, 48-53. http://dx.doi.org/10.1016/j.ijcard.2005.02.034

[150] Erbel, R. and Heusch, G. (1999) Coronary Microembolization-Its Role in Acute Coronary Syndromes and Interventions. Herz, 24, 558-575. http://dx.doi.org/10.1007/BF03044228

[151] Erbel, R. and Heusch, G. (1999) Spontaneous and Iatrogenic Microembolization. A New Concept for the Pathogenesis of Coronary Artery Disease. Herz, 24, 493-495. http://dx.doi.org/10.1007/BF03044219

[152] Appelbaum, E. and Manning, W.J. (2009) Science to Practice: Can the Combination of Resting First-Pass Myocardial Perfusion and Late Gadolinium-Enhanced Cardiovascular MR Imaging Help Identify Myocardial Infarction Resulting from Coronary Microembolization? Radiology, 250, 609-611. http://dx.doi.org/10.1148/radiol.2503082001

[153] Schmidt, A., Azevedo, C.F., Cheng, A., et al. (2007) Infarct Tissue Heterogeneity by Magnetic Resonance Imaging Identifies Enhanced Cardiac Arrhythmia Susceptibility in Patients with Left Ventricular Dysfunction. Circulation, 115, 2006-2014. http://dx.doi.org/10.1161/CIRCULATIONAHA.106.653568

[154] Schuleri, K.H., Centola, M., George, R.T., et al. (2009) Characterization of Peri-Infarct Zone Heterogeneity by Contrast-Enhanced Multidetector Computed Tomography: A Comparison with Magnetic Resonance Imaging. Journal of the American College of Cardiology, 53, 1699-1707. http://dx.doi.org/10.1016/j.jacc.2009.01.056

[155] de Bakker, J.M., van Capelle, F.J., Janse, M.J., et al. (1988) Reentry as a Cause of Ventricular Tachycardia in Patients with Chronic Ischemic Heart Disease: Electrophysiologic and Anatomic Correlation. Circulation, 77, 589-606. http://dx.doi.org/10.1161/01.CIR.77.3.589

[156] Srinivasan, M., Rihal, C., Holmes, D.R. and Prasad, A. (2009) Adjunctive Thrombectomy and Distal Protection in Primary Percutaneous Coronary Intervention: Impact on Microvascular Perfusion and Outcomes. Circulation, 119, 1311-1319. http://dx.doi.org/10.1161/CIRCULATIONAHA.108.831453

[157] Grube, E., Gerckens, U., Yeung, A.C., et al. (2001) Prevention of Distal Embolization during Coronary Angioplasty in Saphenous Vein Grafts and Native Vessels Using Porous Filter Protection. Circulation, 104, 2436-2441. http://dx.doi.org/10.1161/hc4501.099317

[158] Haeck, J.D., Koch, K.T., Bilodeau, L., et al. (2009) Randomized Comparison of Primary Percutaneous Coronary Intervention with Combined Proximal Embolic Protection and Thrombus Aspiration versus Primary Percutaneous Coronary Intervention Alone in ST-Segment Elevation Myocardial Infarction: The PREPARE (PRoximal Embolic Protection in Acute Myocardial Infarction and Resolution of ST-Elevation) Study. JACC: Cardiovascular Interventions, 2, 934-943. http://dx.doi.org/10.1016/j.jcin.2009.07.013

[159] Carlino, M., De Gregorio, J., Di Mario, C., et al. (1999) Prevention of Distal Embolization during Saphenous Vein Graft Lesion Angioplasty. Experience with a New Temporary Occlusion and Aspiration System. Circulation, 99, 32213223. http://dx.doi.org/10.1161/01.CIR.99.25.3221

[160] Hamburger, J.N. and Serruys, P.W. (1997) Treatment of Thrombus Containing Lesions in Diseased Native Coronary Arteries and Saphenous Vein Bypass Grafts Using the AngioJet Rapid Thrombectomy System. Herz, 22, 318-321. http://dx.doi.org/10.1007/BF03044282

[161] Ischinger, T. (2001) Thrombectomy with the X-SIZER Catheter System in the Coronary Circulation: Initial Results from a Multi-Center Study. Journal of Invasive Cardiology, 13, 81-88.

[162] Patel, S. and Hermiller, J. (2008) Embolic Protection: The FilterWire EZ ${ }^{\mathrm{TM}}$ Embolic Protection System. Expert Review of Medical Devices, 5, 19-24. http://dx.doi.org/10.1586/17434440.5.1.19

[163] Svilaas, T., Vlaar, P.J., van der Horst, I.C., et al. (2008) Thrombus Aspiration during Primary Percutaneous Coronary Intervention. The New England Journal of Medicine, 358, 557-567. http://dx.doi.org/10.1056/NEJMoa0706416

[164] Gick, M., Jander, N., Bestehorn, H.P., et al. (2005) Randomized Evaluation of the Effects of filter-Based Distal Protec- 
tion on Myocardial Perfusion and Infarct Size after Primary Percutaneous Catheter Intervention in Myocardial Infarction with and without ST-Segment Elevation. Circulation, 112, 1462-1469.

http://dx.doi.org/10.1161/CIRCULATIONAHA.105.545178

[165] Junghans, U. and Siebler, M. (2003) Cerebral Microembolism Is Blocked by Tirofiban, a Selective Nonpeptide Platelet Glycoprotein IIb/IIIa Receptor Antagonist. Circulation, 107, 2717-2721. http://dx.doi.org/10.1161/01.CIR.0000070544.15890.0E

[166] de Lemos, J.A., Gibson, C.M., Antman, E.M., et al. (2001) Abciximab and Early Adjunctive Percutaneous Coronary Intervention Are Associated with Improved ST-Segment Resolution after Thrombolysis: Observations from the TIMI 14 Trial. American Heart Journal, 141, 592-598. http://dx.doi.org/10.1067/mhj.2001.113574

[167] Kunichika, H., Ben-Yehuda, O., Lafitte, S., Kunichika, N., Peters, B. and DeMaria, A.N. (2004) Effects of Glycoprotein IIb/IIIa Inhibition on Microvascular Flow after Coronary Reperfusion: A Quantitative Myocardial Contrast Echocardiography Study. Journal of the American College of Cardiology, 43, 276-283. http://dx.doi.org/10.1016/j.jacc.2003.08.040

[168] Yang, Y.J., Zhao, J.L., You, S.J., et al. (2006) Different Effects of Tirofiban and Aspirin plus Clopidogrel on Myocardial No-Reflow in a Mini-Swine Model of Acute Myocardial Infarction and Reperfusion. Heart, 92, 1131-1137. http://dx.doi.org/10.1136/hrt.2005.077164

\section{Abbreviations}

Acute Myocardial Infarction (AMI)

Percutaneous Coronary Interventions (PCI)

Microvascular Obstruction (MVO)

Left Ventricular (LV)

Emboli Detection and Classification (EDAC)

F-18 Fluorodeoxyglucose (FDG)

Magnetic Resonance Imaging (MRI)

Multidetector Computed Tomography (MDCT)

Electrocardiography (ECG)

ST-Segment Elevation Myocardial Infarction (STEMI)

No ST-Segment Elevation Myocardial Infarction (NSTEMI)

Tumor Necrosis Factor (TNF $\alpha$ )

Intravascular Ultrasound (IVUS)

Positron Emission Tomography (PET)

Single Photon Emission Computed Tomography (SPECT)

Three Dimensional (3D)

Left Anterior Descending (LAD)

Time to Peak Strain (TTPS)

Enhanced Myocardial Efficacy and Recovery by Aspiration of Liberated Debris (EMERALD)

Glycoprotein (GP) 
Scientific Research Publishing (SCIRP) is one of the largest Open Access journal publishers. It is currently publishing more than 200 open access, online, peer-reviewed journals covering a wide range of academic disciplines. SCIRP serves the worldwide academic communities and contributes to the progress and application of science with its publication.

Other selected journals from SCIRP are listed as below. Submit your manuscript to us via either submit@scirp.org or Online Submission Portal.
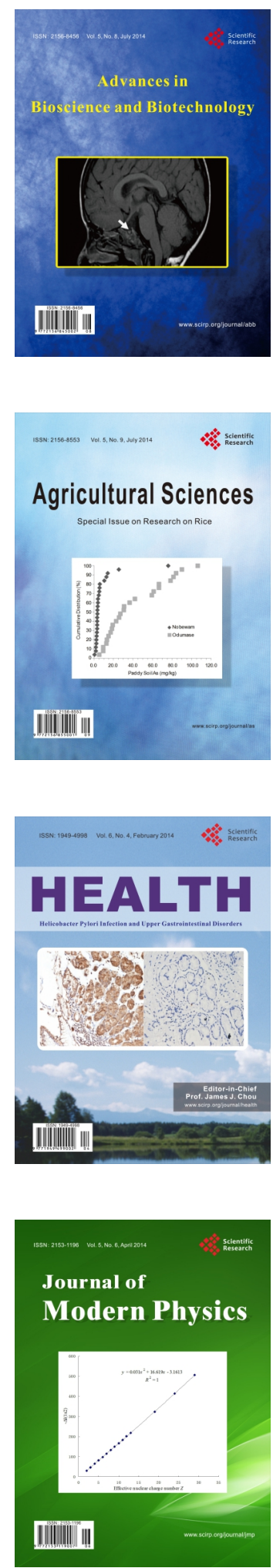
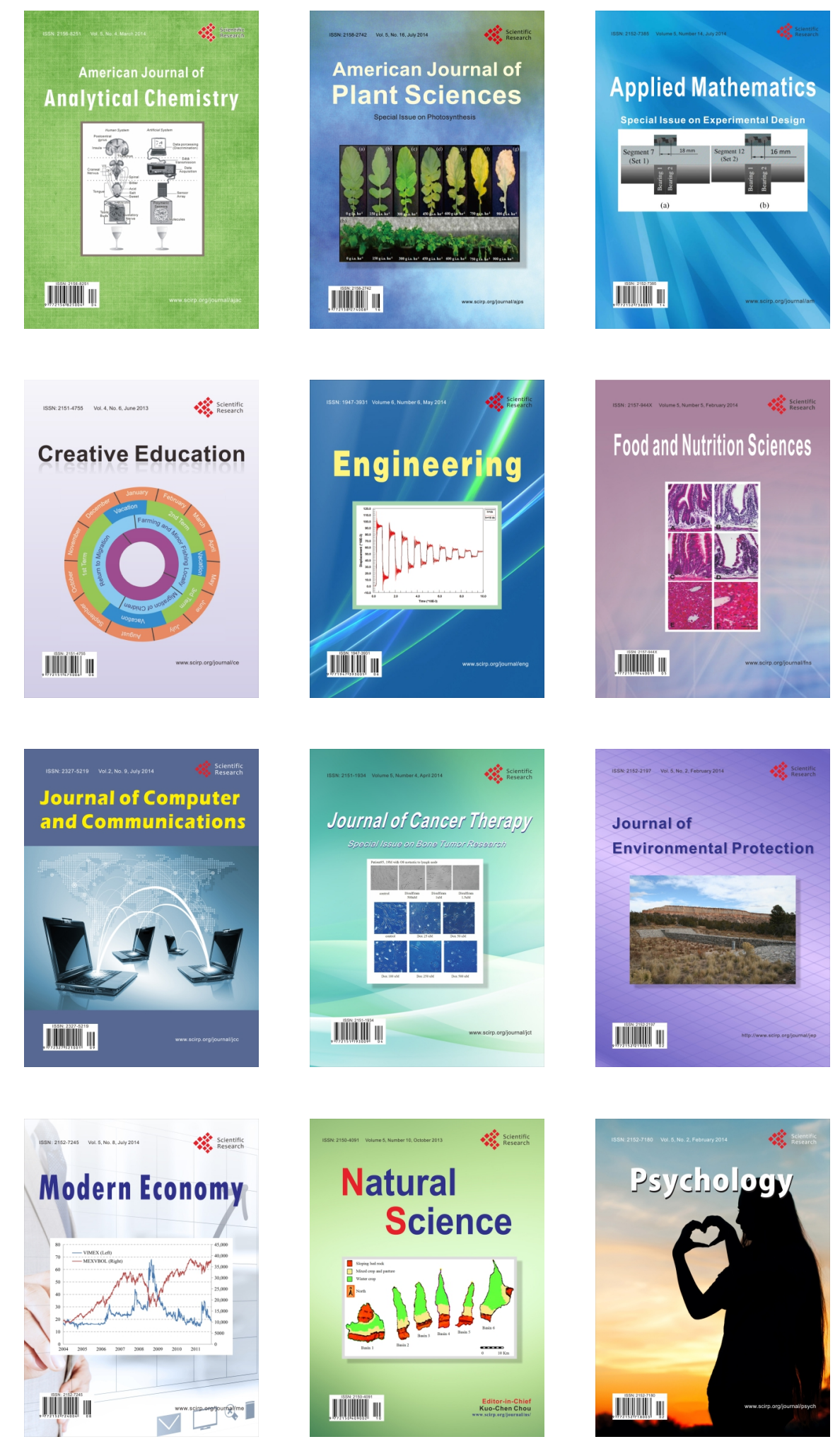